\title{
Amphetamine-Induced Behavior, Dopamine Release, and c-fos mRNA Expression: Modulation by Environmental Novelty
}

\author{
Aldo Badiani, ${ }^{1}$ Matthew M. Oates, ${ }^{1}$ Heidi E. W. Day, ${ }^{2}$ Stanley J. Watson, ${ }^{2}$ Huda Akil, ${ }^{2}$ and Terry E. Robinson ${ }^{1}$ \\ ${ }^{1}$ Biopsychology, Department of Psychology, The University of Michigan, Ann Arbor, Michigan 48109-1109, and \\ 2Mental Health Research Institute and Department of Psychiatry, The University of Michigan, \\ Ann Arbor, Michigan 48109-0720
}

\begin{abstract}
We have shown recently that the psychomotor activating effects of amphetamine in the rat are much greater when this drug is administered in association with environmental novelty than when it is given in a home environment. The main purpose of the present study was to explore the neural basis of this phenomenon. We found, using in situ hybridization of c-fos mRNA, that the pattern of neuronal activation in the cortex, in the caudate, in the shell and core of the nucleus accumbens, and in other subcortical structures was markedly different when amphetamine $(2.0 \mathrm{mg} / \mathrm{kg}$, i.p.) was given in association with exposure to environmental novelty relative to when it was given at home. In most brain regions the magnitude of c-fos expression was over two times greater in rats given amphetamine plus novelty than in rats given amphetamine alone. In contrast, an in vivo microdialysis study indicated that environmental novelty did not affect amphetamine-induced dopamine release in either
\end{abstract}

Psychoactive drugs are thought to produce their effects on behavior, affect, and sensory perceptual functions because of their ability to bind to specific sites in the CNS and thereby to modify ongoing neuronal processes. This simple pharmacological view of drug action is challenged, however, by the common observation that the behavioral and subjective effects of psychoactive drugs vary markedly depending on the circumstances surrounding their use (Kelleher and Morse, 1968; Zinberg, 1984; Barrett, 1987; Falk and Feingold, 1987). Indeed, it has been argued that "the behavioral effects of drugs are determined not only by their intrinsic pharmacological properties, but also by environmental contexts within which they act" [Falk and Feingold (1987), page 1503]. Almost nothing is known, however, about the neurobiological mechanisms by which environmental factors modulate the pharmacological actions of psychoactive drugs.

To address this issue, we recently developed an animal model to study how a relatively simple environmental manipulation modulates the behavioral activating effects of amphetamine. Two groups of rats are given amphetamine in test cages that are physically identical; for one group the cage is a completely novel

Received Aug. 13, 1998; revised Sept. 25, 1998; accepted Sept. 30, 1998.

This work was supported by National Institute on Drug Abuse Grants DA04294, DA08920, and DA02265. We thank Jessica J. Lalley for her help in conducting the microdialysis experiments, Dr. Tom Curran for the c-fos clone, and Dr. Serge Campeau for ancillary software. We also thank Drs. Kent C. Berridge, Michael R. Gorman, and Jane Stewart for their comments on a previous version of this manuscript.

Correspondence should be addressed to Dr. Aldo Badiani, Department of Psychology, The University of Michigan, 525 East University Street, Ann Arbor, MI 48109-1109.

Copyright (ㄷ 1998 Society for Neuroscience $\quad 0270-6474 / 98 / 1810579-15 \$ 05.00 / 0$ caudate or nucleus accumbens. Furthermore, a unilateral 6-hydroxydopamine lesion of the mesostriatal dopamine system reduced amphetamine- but not novelty-induced c-fos expression. Finally, we found no differences in the amount of corticosterone secreted after exposure to novelty, amphetamine, or both, suggesting that corticosterone does not play a critical role in the ability of novelty to modulate amphetamineinduced psychomotor activation. In conclusion, it seems that environmental novelty alters the neurobiological effects of amphetamine independently of the primary neuropharmacological actions of this drug in the striatum.

Key words: amphetamine; environment; context; stress; microdialysis; dopamine; 6-OHDA; rotational behavior; corticosterone; c-fos; striatum; caudate; nucleus accumbens; shell; core; cortex; parietal cortex; somatosensory cortex; septum; claustrum

environment, whereas for the other it is the home cage. The behavioral activating effects of amphetamine are greater when the drug is given in association with environmental novelty (Badiani et al., 1995a,b,c; Crombag et al., 1996), even though there is no effect of environment on the concentration of amphetamine in either plasma or striatum after an intraperitoneal injection (Badiani et al., 1997). This suggests, of course, that the neurobiological consequences of an amphetamine treatment vary as a function of environmental context. The purpose of the present study was to explore how.

The behavioral activating effects of amphetamine are caused primarily by its ability to increase dopamine (DA) release in the terminal regions of the mesotelencephalic DA system, especially in the dorsal (caudate) and ventral (nucleus accumbens) striatum (Wise and Bozarth, 1987; Le Moal, 1995). Thus, in the first experiment we used in vivo microdialysis to determine whether environmental novelty alters the ability of amphetamine to induce DA overflow in either the caudate nucleus or the nucleus accumbens. We found that it did not.

Amphetamine-stimulated DA release, however, is but the first step in a complex chain of neural events that eventually leads to psychomotor activation. Thus, in a second experiment we used c-fos expression as a marker of neuronal activation (Dragunow and Robertson, 1987; Dragunow and Faull, 1989; Morgan and Curran, 1991) to assess the ability of amphetamine to engage specific neural systems as a function of environmental condition. It is well known, for example, that amphetamine produces robust c-fos expression in the striatal complex and other brain regions (Graybiel et al., 1990; Curran et al., 1996; for review, see Harlan 
and Garcia, 1998). The results of this experiment indicate that the neural circuitry engaged by amphetamine varies as a function of the environmental context.

\section{MATERIALS AND METHODS}

\section{Animals}

Seventy-three male Sprague Dawley rats (Harlan Sprague Dawley, Indianapolis, IN), weighing 200-225 gm on their arrival in the laboratory, were initially housed in stainless steel hanging cages in a temperatureand humidity-controlled colony room. The animals were acclimatized to the colony room for 1 week before any experimental manipulation. The rats were kept on a 14:10 hr light/dark cycle (lights on at 6:00 A.M.) and were given food and water ad libitum for the duration of the experiments.

\section{6-Hydroxydopamine lesion}

All rats received a unilateral 6-hydroxydopamine (6-OHDA) lesion of the mesostriatal dopamine system. The rationale for using this preparation has been described in detail elsewhere (see Badiani et al., 1995a,b). In the present experiment it provided an excellent way to quantify not only the psychomotor activating effects of amphetamine, by measuring amphetamine-induced rotational behavior (Ungerstedt and Arbuthnott, 1970), but also the extent to which changes in striatal c-fos expression were DA-dependent.

Before surgical anesthesia was induced with sodium pentobarbital (supplemented with methoxyflurane), the rats were administered atropine and desipramine (the latter to protect noradrenergic terminals). By the use of standard stereotaxic procedures, the rats were then given a unilateral 6-OHDA lesion (right and left sides were counterbalanced) as described previously (Robinson, 1984). Briefly, $8 \mu \mathrm{g}$ of 6-OHDA was infused into the medial forebrain bundle (from bregma: anteroposterior, $-3.0 \mathrm{~mm}$; mediolateral, $\pm 1.4 \mathrm{~mm}$; and dorsoventral, $-8.0 \mathrm{~mm}$ ) over an $8 \mathrm{~min}$ period via a stainless steel cannula. The animals were allowed to recover from surgery for $10 \mathrm{~d}$ and then were given a subcutaneous injection of apomorphine $(0.05 \mathrm{mg} / \mathrm{kg})$ to assess the development of DA receptor supersensitivity, as indicated by the appearance of contraversive rotational behavior. Denervation supersensitivity is a good indicator of the size of the lesion because it occurs only after $90-95 \%$ of DA terminals are destroyed (Hefti et al., 1980a,b). Animals that made less than eight rotations over a 2 min test were excluded from the study. A rotation was defined as four consecutive $90^{\circ}$ turns in the same direction.

\section{Experiment 1: in vivo microdialysis}

Guide cannula surgery. Two weeks after the 6-OHDA lesion, the rats used in the microdialysis experiment underwent a second surgical procedure. By the use of standard stereotaxic procedures, a 8-mm-long 21 gauge guide cannula was cemented to the skull above the caudate $(n=$ $11)$ or the nucleus accumbens $(n=13)$ on the side contralateral to the lesion. A $15 \mathrm{~mm}$ stainless steel post (15 gauge tubing) was also cemented to the skull at this time. This was used later to tether the rats to a liquid swivel during in vivo microdialysis (see below).

Testing procedures. After recovering from the anesthesia, the rats were assigned to one of two groups. The rats in what will be referred to as the "amphetamine + novelty" group $(n=5$, caudate; $n=7$, nucleus accumbens) were housed in square cages $(20.5 \mathrm{~cm} \times 31 \mathrm{~cm}$ and $28 \mathrm{~cm}$ high) made of transparent Plexiglas, with stainless steel grid floors (bars were $1.5 \mathrm{~cm}$ apart). Plastic waste trays filled with pine wood shavings were placed under the cage floors. After $4 \mathrm{~d}$ all rats were tethered via a flexible stainless steel cable to a swivel mounted on a counterbalanced arm located above the cage, which allowed for free movement within the cage. Two days later a microdialysis probe (see below) was inserted into each guide cannula under light ether anesthesia. A perfusion solution (145 $\mathrm{mm} \mathrm{NaCl}, 2.7 \mathrm{~mm} \mathrm{KCl}, 1.2 \mathrm{mM} \mathrm{CaCl}_{2}$, and $1.0 \mathrm{mM} \mathrm{MgCl}_{2}$ ) was pumped through the probes at a flow rate of $0.3 \mu \mathrm{l} / \mathrm{min}$ overnight. The following morning at 9:00 A.M., the flow rate was increased to 1.5 $\mu \mathrm{l} / \mathrm{min}$, and after $3 \mathrm{hr}$, three $30 \mathrm{~min}$ samples (B1-B3) were collected manually. Each rat was then transferred to an opaque plastic cylindrical cage $(25 \mathrm{~cm}$ in diameter and $36 \mathrm{~cm}$ high, with ground corncob bedding on the floor), which was adjacent to the home cage. These cylindrical cages represented a completely novel environment for the rats. Immediately after placement in the novel test cages, the rats were given an intraperitoneal injection of amphetamine $(2.0 \mathrm{mg} / \mathrm{kg})$, and five $20 \mathrm{~min}$ samples (A1-A5) were taken. Thus, the amphetamine + novelty group received amphetamine in association with environmental novelty. Behavior was recorded via video cameras and videocassette recorder (VCR) equipment, and rotational behavior was later quantified by an observer.

At the same time the rats in the other group, which will be called the "amphetamine" group ( $n=6$, caudate; $n=6$, nucleus accumbens), received the same dose of amphetamine and underwent the same microdialysis procedures with one major difference. Immediately after guide cannula surgery, these rats were housed in cages identical to the novel test cages described above (i.e., the cylindrical cages), where they remained until they received amphetamine $7 \mathrm{~d}$ later. Thus, the rats in this group received amphetamine in what had become their home cage. Again, it is important to emphasize that the test environment (an opaque plastic cylindrical cage with ground corncob bedding on the floor) was physically identical for the two groups, including the presence of food and water.

Microdialysis probes. The microdialysis probes were similar to those described previously (Robinson and Camp, 1991) with two major modifications: (1) the metal shaft extended only $1 \mathrm{~mm}$ below bregma, and (2) the dialysis membrane was coated with cyanoacrylic glue except for its distal $2.5 \mathrm{~mm}$ (including a $0.5 \mathrm{~mm}$ glue plug at the end of the probe). These modifications were made to minimize brain damage. The probes were calibrated in vitro at room temperature to determine their ability to recover a known concentration of DA. The coordinates (in millimeters from bregma) for the tip of the microdialysis probes were as follows: anteroposterior, +1.2 ; mediolateral, \pm 3.0 ; and dorsoventral -6.5 , for the caudate; and anteroposterior, +1.6 ; mediolateral, \pm 1.5 ; dorsoventral, -9.0 , for the nucleus accumbens.

Quantification of $D A$. The concentration of DA in dialysate samples was quantified with an HPLC system coupled to an electrochemical detector, using procedures described previously (Robinson and Camp, 1991). A single baseline value for DA was calculated by averaging the values of the three baseline samples and correcting this average for probe recovery. The effect of amphetamine on DA concentrations in dialysate was determined after all values were corrected for probe recovery and converted to the percent of the baseline value.

Histology. At the end of the experiment, the animals were deeply anesthetized with sodium pentobarbital and perfused transcardially with a $0.9 \%$ saline solution and then with a $10 \%$ formalin solution. Brains were stored in a $10 \%$ formalin solution for at least $4 \mathrm{~d}$ and then sliced into $40 \mu \mathrm{m}$ coronal sections. Histological verification was made on cresyl violet-stained sections with reference to the stereotaxic atlas of Paxinos and Watson (1982). The distribution of the sampling portion of the probes considered to be correctly placed is shown in Figure 1.

\section{Experiment 2: in situ hybridization}

Testing procedures. Four days after the apomorphine screen, three groups of rats were housed in opaque plastic cylindrical cages with ground corncob bedding, identical to the test cages used in the microdialysis experiment. Seven days later (thus, for the rats in this group the test cage had become the home cage) at $\sim 12: 10$ P.M., one group received an intraperitoneal injection of saline (saline group; $n=9$ ), another group received an intraperitoneal injection of amphetamine $(2.0 \mathrm{mg} / \mathrm{kg}$; amphetamine group; $n=12$ ), and the third group remained undisturbed (untreated group; $n=7$ ). Two other groups of rats also received an intraperitoneal injection of either saline (novelty group; $n=9$ ) or amphetamine $(2.0 \mathrm{mg} / \mathrm{kg}$; amphetamine + novelty group; $n=11)$ but under different environmental conditions. These rats were transported from the animal colony room, where they lived in stainless steel hanging cages, to the cylindrical cages described above (which represented therefore a completely novel environment) and immediately administered the intraperitoneal injection. At $\sim 1: 00$ P.M. (that is $50 \mathrm{~min}$ after the treatment with amphetamine or saline), the rats were decapitated, and their brains were removed, immediately frozen in isopentane $\left(-40\right.$ to $\left.-50^{\circ} \mathrm{C}\right)$, and stored at $-70^{\circ} \mathrm{C}$. In addition, trunk blood was collected in tubes containing EDTA and placed on ice for analysis of plasma corticosterone (see below). Behavior was videotaped for a $5 \mathrm{~min}$ period (45-50 min after the treatment) immediately before decapitation, and rotational behavior was later quantified.

In situ hybridization of $c$-fos $m R N A$. Coronal brain sections $(10 \mu \mathrm{m})$ were cut on a cryostat (at $200 \mu \mathrm{m}$ intervals from approximately $+2.2 \mathrm{~mm}$ to $-1.7 \mathrm{~mm}$ relative to bregma) and thaw-mounted onto polylysinecoated slides. The slides were then air dried and stored at $-70^{\circ} \mathrm{C}$ until processing for in situ hybridization. The in situ hybridization method was adapted from the protocol described by Cullinan et al. (1995). A 680-mer ${ }^{35}$ S-labeled cRNA probe complementary to c-fos mRNA (courtesy of Dr. T. Curran, St. Jude Children's Research Hospital, Memphis, TN) was 


\section{Caudate}
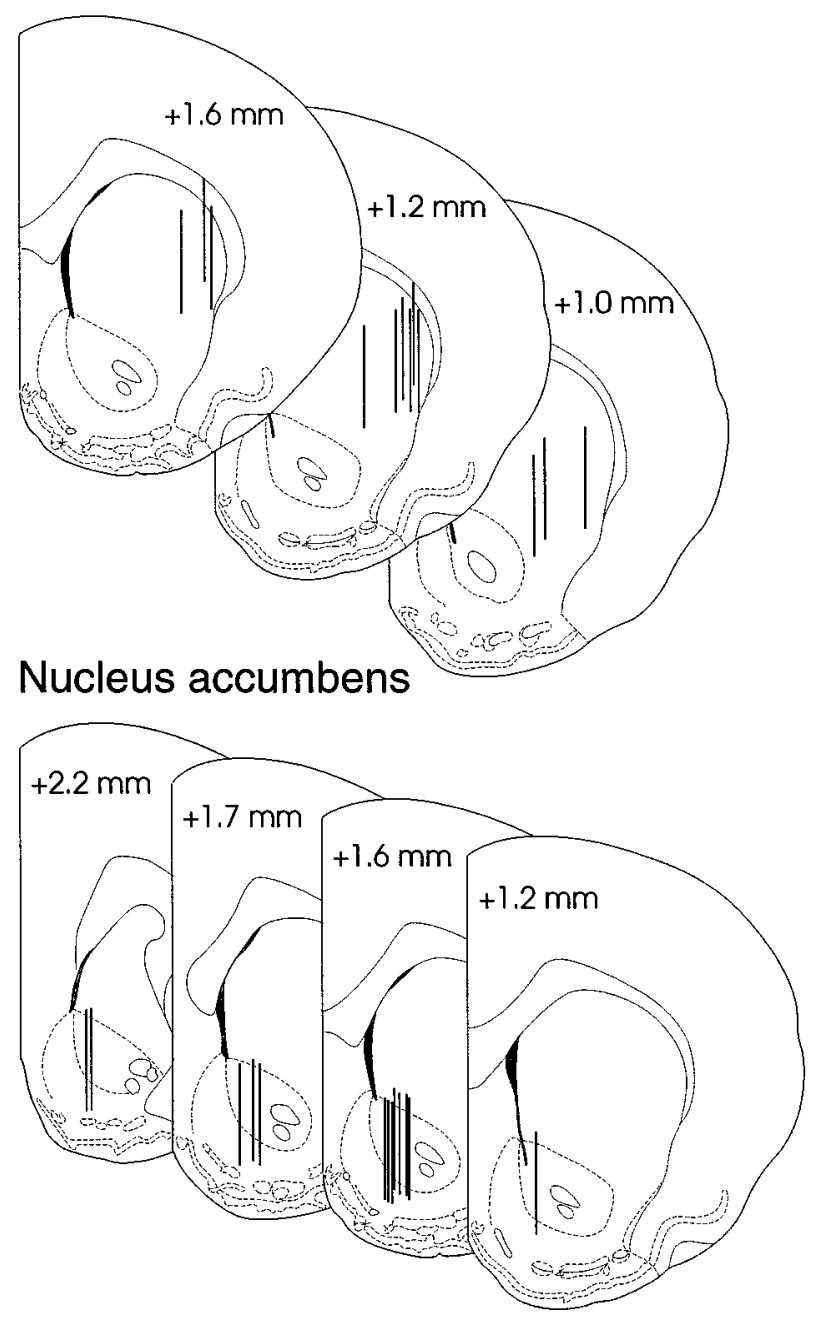

Figure 1. Schematic drawings illustrating the placement (vertical lines) of the microdialysis probes. This figure was obtained by digital modification of plates from Paxinos and Watson (1982). The values in millimeters indicate distance from bregma.

used. Linearized plasmid $(1 \mu \mathrm{g})$ was incubated at $37^{\circ} \mathrm{C}$ for $2 \mathrm{hr}$ in $1 \times$ transcription buffer (BRL, Bethesda, MD), $75 \mu \mathrm{Ci}$ of $\alpha{ }^{-35}{ }^{35}$-UTP $(>1000$ $\mathrm{Ci} / \mathrm{mmol} ; 20 \mathrm{mCi} / \mathrm{ml}$; Amersham, Arlington Heights, IL), $100 \mu \mathrm{Ci}$ of $\alpha-{ }^{35} \mathrm{~S}-\mathrm{CTP}$ (800 Ci/mmol; $40 \mathrm{mCi} / \mathrm{ml}$; Amersham), $400 \mu \mathrm{M} \mathrm{ATP,} 400 \mu \mathrm{M}$ GTP, $10 \mathrm{~mm}$ dithiothreitol (DTT), $20 \mathrm{U}$ of RNase inhibitor, and $6 \mathrm{U}$ of T7 RNA polymerase. The resulting probe was separated from free nucleotides on a Sephadex G50-50 column. The specificity of the probe was assessed in control experiments using sense probes or tissue that had been pretreated with RNase A $(200 \mu \mathrm{g} / \mathrm{ml})$ for $1 \mathrm{hr}$ at $37^{\circ} \mathrm{C}$, before hybridization with antisense probes. No specific hybridization was observed for any of the controls.

Before hybridization, brain sections were placed in $4 \%$ phosphatebuffered paraformaldehyde, fixed for $1 \mathrm{hr}$, and rinsed three times in $2 \times$ SSC. The slides were then placed in a solution of $0.1 \mathrm{M}$ triethanolamine and $0.25 \%$ acetic acid for $10 \mathrm{~min}$, rinsed in water, and dehydrated through a series of alcohols. The ${ }^{35} \mathrm{~S}$-labeled probe was diluted in hybridization buffer ( $50 \%$ formamide, $10 \%$ dextran sulfate, $3 \times \mathrm{SSC}, 50 \mathrm{~mm}$ sodium phosphate buffer, $\mathrm{pH} 7.4,1 \times$ Denhardt's solution, $0.1 \mathrm{mg} / \mathrm{ml}$ yeast tRNA, and $10 \mathrm{~mm}$ DTT) to yield an approximate concentration of $2-2.5 \times 10^{6} \mathrm{cpm} / 65 \mu \mathrm{l}$. Each slide was covered with $65 \mu \mathrm{l}$ of diluted probe and then coverslipped. The slides were then placed in plastic trays lined with filter paper dampened with $50 \%$ formamide $/ 50 \%$ water. The trays were sealed and incubated at $55^{\circ} \mathrm{C}$ for $16 \mathrm{hr}$. Coverslips were floated off in $2 \times$ SSC, and slides were rinsed an additional three times in $2 \times$ SSC. The sections were then incubated in RNase A $(200 \mu \mathrm{g} / \mathrm{ml})$ at $37^{\circ} \mathrm{C}$ for $60 \mathrm{~min}$; rinsed in $2 \times, 1 \times, 0.5 \times$, and $0.1 \times \mathrm{SSC}$; washed to a final stringency of $0.1 \times \mathrm{SSC}$ at $70^{\circ} \mathrm{C}$ for $60 \mathrm{~min}$; cooled to room temperature in $0.1 \times$ SSC; and finally dehydrated through a series of alcohols.

To obtain autoradiographs of the sections, we exposed the slides to $\mathrm{x}$-ray film (Kodak Biomax-MR) for $4 \mathrm{~d}$ and then dipped the slides in emulsion (Kodak NTB2) and stored them in light-tight boxes at $4^{\circ} \mathrm{C}$ for $14 \mathrm{~d}$. After development (Kodak D-19), the slides were coverslipped with Permount for qualitative analysis by light microscopy.

Quantification of $c$-fos $m R N A$ and data analysis. All data were obtained from the same in situ hybridization experiment. The autoradiographs were digitized, and the magnitude of the signal from the hybridized ${ }^{35}$ S-cRNA probe was determined using National Institutes of Health Image software. The program analyzed the distribution of optical density (OD) values (arbitrary units) of pixels within a "background" region (in this case the corpus callosum) to yield a threshold value (mean OD of background + 3.5 SD; macro written by Dr. S. Campeau, University of Michigan, Ann Arbor, MI). Only pixels that were above threshold (signal pixels) were used for the densitometric analysis. The "net" OD of these signal pixels was obtained by subtracting the threshold value. To compare c-fos mRNA expression in brain regions of different size, we expressed the OD as the mean net OD of signal pixels divided by the total number of pixels in the region. Each densitogram was subdivided for analysis in the areas identified and was labeled on the basis of the stereotaxic atlas of Paxinos and Watson (1982).

The striatal complex was subdivided into the caudate, the shell of the nucleus accumbens, and the core of the nucleus accumbens. The average optical density in the intact side of the caudate was calculated over nine levels $(+2.2,+1.6,+1.2,+0.8,+0.2,-0.2,-0.8,-1.3$, and $-1.7 \mathrm{~mm}$ relative to bregma), and that in the nucleus accumbens was over five levels $(+2.2,+2.0,+1.8,+1.6$, and $+1.2 \mathrm{~mm})$.

Other regions analyzed (intact side) were the cingulate cortex ( $\mathrm{Cg} 1 /$ $\mathrm{Cg} 2)$, the motor cortex (Fr1/Fr2), the sensory motor cortex (FL/HL), area Par1 of the primary somatosensory cortex, the secondary somatosensory cortex (Par2), the piriform cortex (Pir), the claustrum $(\mathrm{Cl})$, the dorsal endopiriform nucleus (DEn), and the septum. The values for $\mathrm{Cg} 1 / \mathrm{Cg} 2, \mathrm{Fr} 1 / \mathrm{Fr} 2$, Par2, Pir, Cl, and DEn were calculated at three levels $(+1.6,+0.5$, and $-1.3 \mathrm{~mm})$; those for $\mathrm{FL} / \mathrm{HL}$ were calculated at three levels $(+1.2,+0.5$, and $-1.3 \mathrm{~mm})$; and those for Par1 were calculated at 10 levels $(+2.2,+1.6,+1.2,+0.8,+0.5,+0.2,-0.2,-0.8,-1.3$, and -1.7 $\mathrm{mm})$. The septum was analyzed (bilaterally) only at one level $(+0.5 \mathrm{~mm})$ after being subdivided into the dorsal (LSI and LSD) and ventral (MS, $\mathrm{VDB}$, and HDB) septum.

The effect of the 6-OHDA lesion on c-fos mRNA levels was assessed by comparing the values on the intact and lesion sides for the caudate (average of levels $+1.2,+0.2$, and $-1.3 \mathrm{~mm}$ ) and for the shell and core of the nucleus accumbens (average of levels $+2.2,+1.8$, and $+1.2 \mathrm{~mm}$ ).

Plasma corticosterone. Plasma levels of corticosterone were determined by radioimmunoassay using antibody to rat corticosterone raised and characterized by Dr. D. L. Helmreich of the Mental Health Research Institute of the University of Michigan (Day and Akil, 1996). The cross-reactivity with other steroids (cortisol, deoxycorticosterone, aldosterone, testosterone, and progesterone) was $<3 \%$. The blood samples were spun at $2500 \mathrm{rpm}$ (Sorvall RC-5C), and plasma aliquots were stored at $-20^{\circ} \mathrm{C}$. A $0.05 \mathrm{M}$ sodium phosphate buffer with $0.25 \%$ bovine serum albumin (BSA), pH 7.4, was used for all dilutions. The plasma was diluted $1: 100$, and corticosterone was separated from binding protein by heating the samples to $70^{\circ} \mathrm{C}$ for $30 \mathrm{~min}$. Duplicate diluted plasma samples $(200$ $\mu \mathrm{l})$ and standard concentrations of corticosterone $(0-8000 \mathrm{pg} / \mathrm{ml})$ were incubated at $4^{\circ} \mathrm{C}$ overnight together with $50 \mu$ of $\left[{ }^{3} \mathrm{H}\right]$ corticosterone $(50$ $\mathrm{Ci} / \mathrm{mmol} ; 10,000 \mathrm{cpm} /$ tube; Amersham) and $50 \mu \mathrm{l}$ of antibody (final concentration, 1:12,800). Bound and free corticosterones were separated by addition of $0.5 \mathrm{ml}$ of ice-cold $1 \%$ charcoal $/ 0.1 \%$ dextran. The samples were incubated on ice for $10 \mathrm{~min}$ and spun for $8 \mathrm{~min}$ at $3000 \mathrm{rpm}$ (Sorvall $\mathrm{RC}-5 \mathrm{~B})$. The supernatant was collected and counted for bound $\left[{ }^{3} \mathrm{H}\right] \mathrm{cor}-$ ticosterone. After subtraction of nonspecific binding, concentrations of plasma corticosterone were calculated by comparison with the standard curve. All samples were run in a single assay. Intra-assay variation was $\pm 1.05 \mu \mathrm{g} / \mathrm{dl}$.

\section{Drugs}

Atropine methyl nitrate was dissolved $(0.5 \mathrm{mg} / \mathrm{ml})$ in saline and administered intraperitoneally $(0.2 \mathrm{mg} / \mathrm{kg})$. Nembutal $(64.8 \mathrm{mg}$ of sodium pentobarbital in $1 \mathrm{ml}$ of $10 \%$ ethanol solution; The Butler Company, Columbus, $\mathrm{OH}$ ) was given at the dose of $52.0 \mathrm{mg} / \mathrm{kg}$. Metofane (methoxyflurane; Mallinckrodt Veterinary, Mundelein, IL) was used to supplement the 
anesthesia. 6-Hydroxydopamine (2,4,5-trihydroxyphenethylamine) hydrobromide was freshly dissolved $(2 \mathrm{mg} / \mathrm{ml})$ in a cold solution of $0.9 \mathrm{mg} / \mathrm{ml}$ $\mathrm{NaCl}$ (saline) and $0.1 \mathrm{mg} / \mathrm{ml} \mathrm{L}$-ascorbic acid. Desipramine hydrochloride was dissolved $(15 \mathrm{mg} / \mathrm{ml})$ in distilled water and given intraperitoneally (15 $\mathrm{mg} / \mathrm{kg})$. Apomorphine hydrochloride was freshly dissolved $(0.1 \mathrm{mg} / \mathrm{ml})$ in saline and $0.1 \mathrm{mg} / \mathrm{ml}$ of L-ascorbic acid and was injected subcutaneously in the nape of the neck $(0.05 \mathrm{mg} / \mathrm{kg})$. D-Amphetamine sulfate was dissolved $(2.0 \mathrm{mg} / \mathrm{ml})$ in saline and injected intraperitoneally. All drug weights refer to the weight of the salts. All drugs, except pentobarbital and methoxyflurane, were purchased from Sigma (St. Louis, MO).

\section{Statistical analysis}

Experiment 1. Group differences in rotational behavior and in dialysate DA were analyzed with two-way ANOVAs with repeated measures on one factor (environment, two levels including home and novelty; time, five levels). Group differences in baseline DA were assessed with Student's $t$ tests. All $n$ values for this experiment refer to the animals included in the statistical analysis after histological verification of probe placement.

Experiment 2. Group differences in rotational behavior were analyzed with a one-way ANOVA (group, five levels including untreated, saline, novelty, amphetamine, and amphetamine + novelty), followed by Fisher's PLSD (protected least significant difference) tests for pairwise comparisons. Behavioral data for three rats in the untreated group and for two rats in the saline group were lost because of malfunctioning of the VCR equipment. Group differences in c-fos mRNA levels were analyzed with a one-way ANOVA (group, five levels), followed by Fisher's PLSD tests. Furthermore, c-fos mRNA levels in the caudate and in the core and shell of the nucleus accumbens of the amphetamine + novelty group were compared with "expected" values predicted by a simple additive model of amphetamine and novelty interaction. These expected values were obtained by adding the values for the amphetamine and novelty groups (after subtracting from both the value for the untreated group). One-sample Student's $t$ tests were used to compare the values for the amphetamine + novelty group (minus the value for the untreated group) versus the expected value. The effects of the 6-OHDA lesion on c-fos expression in the caudate and in the core and shell of the nucleus accumbens were analyzed with two-way ANOVAs with repeated measures on one factor (group, five levels; lesion, two levels); paired $t$ tests were used to establish the effect of lesion in each group. A few densitograms were not suitable for analysis because of the poor condition of the sections. In such cases the data were not used in the statistical analysis. Group differences in plasma corticosterone were analyzed with a one-way ANOVA (group, five levels), followed by Fisher's PLSD tests.

The statements made in the Results section are based on the following critical comparisons. (1) The rats in the untreated group remained undisturbed in their home cages until they were killed, whereas the rats in the saline group received an injection of saline in their home cage 50 min before decapitation. Thus, the effect of being picked up and receiving an intraperitoneal injection is indicated by the comparison between the untreated and saline groups. (2) The rats in the novelty group were transferred from their home cage to a novel environment, given an intraperitoneal injection of saline, and allowed to remain there for 50 min before decapitation. The effects of exposure to environmental novelty alone were indicated by a comparison between this group and the saline group. (3) Rats in the amphetamine group received amphetamine in their home cage $50 \mathrm{~min}$ before decapitation. The effects of amphetamine alone were indicated by a comparison between this group and the saline group. (4) Rats in the amphetamine + novelty group were transferred from their home cage to a novel environment, given amphetamine, and allowed to remain there for $50 \mathrm{~min}$ before decapitation. Comparisons between this group and the novelty and amphetamine groups indicated the extent to which amphetamine and novelty interacted.

\section{RESULTS}

\section{Experiment 1: in vivo microdialysis}

The purpose of this experiment was to determine whether the enhancement in amphetamine-induced psychomotor activation seen in animals given the drug in association with environmental novelty is accompanied by an increase in the ability of amphetamine to elevate the extracellular concentration of DA in the caudate or in the nucleus accumbens, that is, whether the effect of environment is to modulate the primary neuropharmacological action of amphetamine. In previous experiments we found that exposure to a novel environment alone produces only modest changes $(+50-100 \%)$ in dialysate DA in the caudate and nucleus accumbens (A. Badiani and T. E. Robinson, unpublished observations). It is conceivable, however, that the effect of novelty on DA overflow could interact synergistically with that of amphetamine, thereby producing much greater DA overflow in animals that receive amphetamine in a novel versus a home environment.

\section{Behavior}

Figure $2 A$ illustrates the time course of amphetamine-induced rotational behavior in animals that underwent in vivo microdialysis either in their home cages (amphetamine group) or in novel test cages (amphetamine + novelty group). The animals in both groups were inactive before drug treatment. Amphetamine elicited a robust psychomotor response, which reached a maximum between 40 and $80 \mathrm{~min}$ after drug treatment. The magnitude of amphetamine-induced rotational behavior, however, was much greater in the group that received amphetamine in association with environmental novelty than in the group given amphetamine in their home cage $(p<0.001)$.

\section{$D A$ concentrations in dialysate}

Figure 2, $B$ and $C$, illustrates the effect of amphetamine on the concentration of DA in dialysate obtained from the caudate (Fig. $2 B$ ) or the nucleus accumbens (Fig. $2 C$ ) of rats that received amphetamine in either their home cages or in novel test cages. There were no group differences in the basal concentrations of $\mathrm{DA}$ in the caudate $(2.24 \pm 0.55$ vs $1.23 \pm 0.28 \mathrm{pg} / \mu \mathrm{l}$ in the amphetamine and the amphetamine + novelty groups, respectively; $p=0.12)$ or in the nucleus accumbens $(0.96 \pm 0.15$ vs $0.93 \pm 0.20 \mathrm{pg} / \mu \mathrm{l} ; p=0.91)$. Amphetamine produced a 10 -fold increase in DA concentrations in both the caudate (Fig. 2B) and the nucleus accumbens (Fig. 2C). Despite the marked group differences in amphetamine-induced rotational behavior, however, there were no group differences in the ability of amphetamine to elevate dialysate DA concentrations in either the caudate $(p=0.92)$ or the nucleus accumbens $(p=0.86)$.

The time course of amphetamine-induced DA overflow was different from the time course of rotational behavior. In the animals that received amphetamine in association with environmental novelty, rotational behavior plateaued between 40 and 100 min after drug treatment. In contrast, DA concentrations in both the caudate and nucleus accumbens peaked earlier (20-40 min interval) and then declined to approximately one-half of the maximum value by the end of the session. That is, the rate of rotational behavior continued to increase while DA concentrations were returning to baseline. A similar pattern was evident in the group treated with amphetamine at home. In addition to this temporal dissociation, there was a quantitative dissociation, as indicated by the absence of a significant correlation between the magnitude of DA overflow and the rate of rotational behavior in either the caudate $(r=0.22 ; p=0.52)$ or the nucleus accumbens $(r=0.06 ; p=0.85)$ (data not shown).

In summary, there was a triple dissociation between the effects of amphetamine on DA overflow and rotational behavior. First, there was no correlation between the rate of amphetamineinduced rotational behavior and DA overflow in either the caudate or nucleus accumbens. Second, there was a temporal dissociation between the effects of amphetamine on DA overflow and behavior (see Fig. 3). Third, and most important, the rate of 

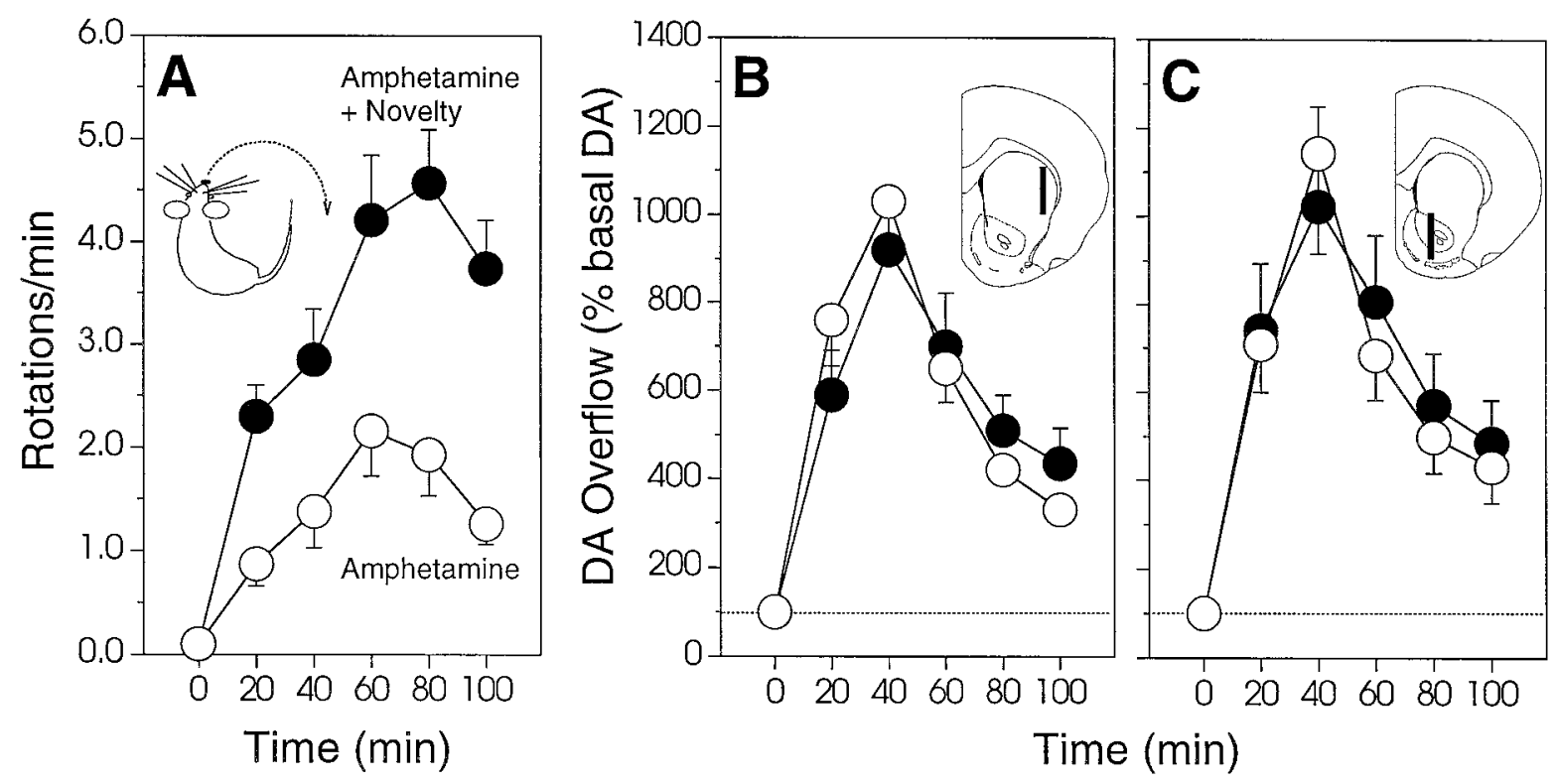

Figure 2. Effects of amphetamine on rotational behavior and striatal DA overflow in animals exposed to amphetamine alone (Amphetamine) or to amphetamine in association with environmental novelty (Amphetamine + Novelty). $A$, Mean $( \pm \mathrm{SEM})$ number of rotations during a 100 min test session. Baseline activity (time 0) was negligible. A two-way ANOVA with repeated measures on one factor indicated a significant effect of environment $\left[F_{(1,23)}=15.54 ; p<0.001\right]$ and of time $\left[F_{(4,92)}=18.14 ; p<0.0001\right]$ and an environment times time interaction $\left[F_{(4,92)}=2.82 ; p=0.029\right] . B, C$, Mean ( \pm SEM) DA concentrations in the dialysates expressed as the percent of the baseline value (mean DA concentration in the 60 min before treatment; time 0). A two-way ANOVA with repeated measures on one factor indicated no effect of environment in either the caudate $\left[B ; F_{(1,9)}=0.01 ; p=0.92\right]$ or the nucleus accumbens $\left[C ; F_{(1,11)}=0.03 ; p=0.86\right]$.

rotational behavior in animals treated with amphetamine in a novel environment was more than twice that seen in animals treated in their home cages, but the effect of amphetamine on DA overflow was the same in the two groups. As illustrated in Figure 1 , however, the largest portion of the sampling surface of the microdialysis probes $(90-60 \%)$ was located in the core of the nucleus accumbens. Given the well documented differences between the core and shell subdivisions of the nucleus accumbens, it might be speculated that environmental novelty modulates amphetamine-induced DA release only in the shell region. It is important to note, therefore, that in a recent study we found no effect of environmental novelty on the ability of amphetamine to increase DA overflow in the shell of the nucleus accumbens either (Browman et al., 1995).

These findings suggest that environmental novelty does not potentiate the effect of amphetamine on rotational behavior by modulating its primary neuropharmacological action in the striatum, which is to increase DA release (Seiden et al., 1993). Our data are consistent with the report by Bardo et al. (1990) that the enhancement in locomotion induced by environmental novelty is not coupled with changes in DA synthesis or metabolism and lend further support to the hypothesis that the psychomotor activating effects of amphetamine are not a simple function of its ability to increase DA release in the striatum [for a discussion of this issue, see Segal and Kuczenski (1994)].

\section{Experiment 2: in situ hybridization}

Given that environmental novelty does not seem to influence the primary neuropharmacological action of amphetamine on mesostriatal DA neurons, we next sought to identify potential sites in the nervous system where amphetamine and novelty interact. We did this by using c-fos expression as a marker of neuronal activation (Dragunow and Robertson, 1987; Dragunow and Faull, 1989; Morgan and Curran, 1991), because there are many reports that both psychostimulant drugs and stressors (such as exposure to novelty) induce the expression of this immediate early gene throughout the striatal complex and in a number of cortical regions (Graybiel et al., 1990; Cullinan et al., 1995; Harlan and Garcia, 1998). Thus, this approach allowed us to assess whether the neural circuitry engaged after treatment with amphetamine varies as a function of environmental context.

In the following we first present the behavioral results (Fig. 3) and then the densitometric analysis of c-fos expression (see Figs. 4-11). Figure 4 shows 15 representative densitograms taken from three different levels of the neuroaxis, illustrating c-fos mRNA levels as a function of environmental condition and drug treatment. It is obvious from even a cursory examination of this figure that there were large group differences in c-fos expression in many brain regions. The outcomes of quantitative analyses of c-fos mRNA levels in the caudate and nucleus accumbens are illustrated in subsequent figures (see Figs. 5-7). Next, we present the results for other selected cortical and subcortical areas (see Figs. 9-11).

\section{Behavior}

Figure 3 shows the rate of rotational behavior during the $5 \mathrm{~min}$ period immediately before decapitation (45-50 min after administration of amphetamine, exposure to environmental novelty, or both). The untreated, saline, and novelty groups showed negligible rotational behavior. As expected, amphetamine produced a marked increase in rotational behavior, and the magnitude of this response was greatest in the rats that received amphetamine in association with environmental novelty $(p=0.004)$.

c-fos expression in the caudate and nucleus accumbens

Controls. It can be seen in Figure 5 [which shows values averaged over the entire rostrocaudal extent of the caudate and nucleus accumbens (see below)] that very low levels of c-fos expression were found in both the caudate and nucleus accumbens of rats in 


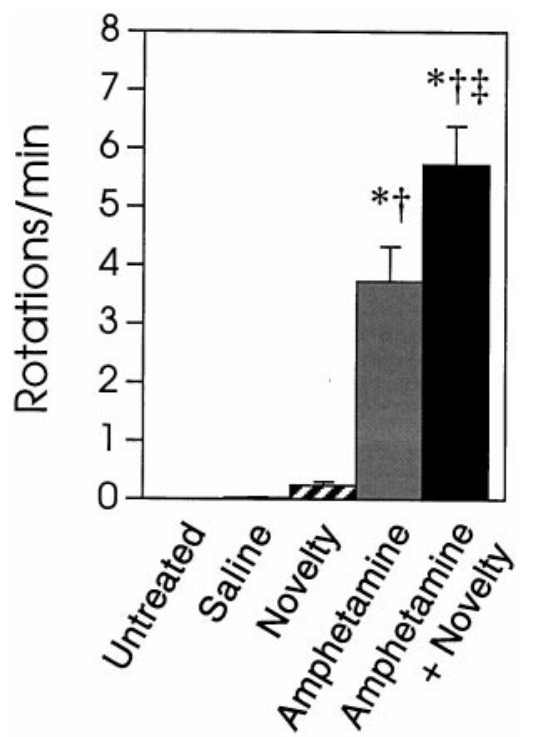

Figure 3. Rate of rotational behavior (mean number of rotations/5 $\min \pm \mathrm{SEM}$ ) as a function of treatment and of environmental condition. The behavior was quantified immediately before decapitation in untreated animals (Untreated) or 45-50 min after an intraperitoneal injection of saline (Saline), an intraperitoneal injection of amphetamine (Amphetamine; $2.0 \mathrm{mg} / \mathrm{kg}$ ), exposure to environmental novelty (Novelty), or exposure to both amphetamine and novelty (Amphetamine + Novelty). A one-way ANOVA indicated significant group differences $\left[F_{(4,38)}=24.56\right.$; $p<0.0001]$. Asterisks indicate a difference from saline $(p<0.05)$; a dagger indicates a difference from novelty $(p<0.05)$; and double daggers indicate a difference from amphetamine $(p<0.05)$.

the untreated and saline groups. In addition, these two groups did not differ significantly from each other, indicating that there was no effect of handling and of the intraperitoneal injection procedure on c-fos expression in the striatal complex.

Novelty. Mere exposure to a novel environment significantly increased c-fos mRNA levels in the caudate $(p=0.005$, all comparisons relative to the saline group) and in the shell $(p<$ $0.0001)$ and core $(p<0.0001)$ of the nucleus accumbens (Fig. 5). The magnitude of this effect, however, was different in the three structures. The greatest increase was in the shell, and the smallest was in the caudate, with intermediate values in the core. Within the caudate, c-fos mRNA levels were greater in the dorsomedial than in the dorsolateral quadrant (see Fig. 4).

Amphetamine. Amphetamine alone also produced a significant increase in c-fos expression in the caudate $(p<0.0001)$ and in the shell $(p=0.001)$ and core $(p<0.0001)$ of the nucleus accumbens (Fig. 5). In contrast to the effect of novelty alone, however, the greatest increase was seen in the caudate, and the smallest was in the shell, with intermediate values in the core. But similar to novelty, the effect of amphetamine on c-fos expression within the caudate was greater in the dorsomedial than in the dorsolateral quadrant (see Fig. 4).

Amphetamine + novelty. The administration of amphetamine in a novel environment (the amphetamine + novelty group) also significantly increased c-fos mRNA levels in the caudate $(p<$ $0.0001)$ and in the shell $(p<0.0001)$ and core $(p<0.0001)$ of the nucleus accumbens (Fig. 5), and as in the amphetamine and novelty groups, c-fos expression within the caudate was greater in the dorsomedial than in the dorsolateral quadrant. However, Figure 5 also illustrates three major group differences. First, amphetamine + novelty produced significantly greater c-fos ex- pression than did amphetamine alone in both the caudate $(p<$ $0.0001)$ and the nucleus accumbens ( $p<0.0001$ in the shell; $p<$ 0.001 in the core). Second, amphetamine + novelty produced greater c-fos expression than did novelty alone in the caudate $(p<0.0001)$ and in the core of the nucleus accumbens $(p<$ $0.0001)$ but, interestingly, not in the shell of the accumbens $(p=$ 0.15). Third, depending on the structure, the effect of amphetamine + novelty on c-fos mRNA levels was either significantly greater than would be predicted by the simple addition of the effects of amphetamine and novelty (as in the caudate; $p=0.021$; see Fig. 5), significantly smaller than would be predicted by the simple addition of the effects of amphetamine and novelty (as in the shell of the nucleus accumbens; $p=0.055$ ), or similar to what would be predicted by the simple addition of the effects of amphetamine and novelty (as in the core of the nucleus accumbens; $p=0.098)$.

$c$-fos $m R N A$ levels and rate of rotational behavior. Figure $5, D-F$, illustrates the relationship between the rate of rotational behavior and c-fos mRNA levels in the caudate (Fig. $5 D$ ) and in the core (Fig. $5 E$ ) and shell (Fig. $5 F$ ) of the nucleus accumbens. For the caudate there was a significant positive correlation between these two variables in both the amphetamine $(r=0.68 ; p=0.015)$ and the amphetamine + novelty groups $(r=0.71 ; p=0.015)$, and the slopes of the two correlation lines were similar to each other and to that of the overall correlation when these two groups were pooled $(r=0.75 ; p<0.0001)$. In contrast, there was no correlation between the rate of amphetamine-induced rotational behavior and c-fos expression in either the shell (Fig. $5 F$ ) or the core (Fig. $5 E$ ) of the nucleus accumbens.

Rostrocaudal differences. Inspection of the densitograms shown in Figure 4 suggested that there might be pronounced group differences in c-fos expression as a function of rostrocaudal level, especially in the caudate, and therefore optical density in this structure was quantified over nine different levels. The results of this analysis are presented in Figure 6. In the two control groups c-fos expression was homogenously low throughout the rostrocaudal extent of the caudate. In contrast, there were distinct rostrocaudal gradients in c-fos expression in the caudate of rats exposed to novelty, amphetamine, or both. The effect of novelty on c-fos expression progressively increased between +2.2 and $+0.8 \mathrm{~mm}$ rostral to bregma, then decreased a little, and remained relatively constant between +0.2 and $-1.7 \mathrm{~mm}$ from bregma. Amphetamine alone had its maximal effect in the midcaudate (between +0.8 and $-0.2 \mathrm{~mm}$ from bregma) and much less effect in the most rostral and caudal portions of the caudate. A third pattern was seen in the amphetamine + novelty group. In this group c-fos expression progressively increased from relatively low levels in the rostral caudate to very high levels that were maintained throughout the middle and caudal portions of the caudate (between +0.8 and $-1.7 \mathrm{~mm}$ from bregma).

It is obvious from inspection of Figure 6 that because of group differences in rostrocaudal patterns of c-fos expression that the amphetamine + novelty group differed from both the amphetamine and the novelty groups to the greatest extent in the most caudal portions of the caudate. Indeed, in the caudal caudate the effect of amphetamine + novelty on c-fos mRNA levels was nearly two times greater than would be predicted by the simple addition of the effects of amphetamine and novelty alone.

A similar analysis of rostrocaudal patterns of c-fos expression over five levels in the core and shell of the nucleus accumbens $(+2.2$ to $+1.2 \mathrm{~mm}$ from bregma) showed no significant rostrocaudal gradient in any group (data not shown). Thus, for the 


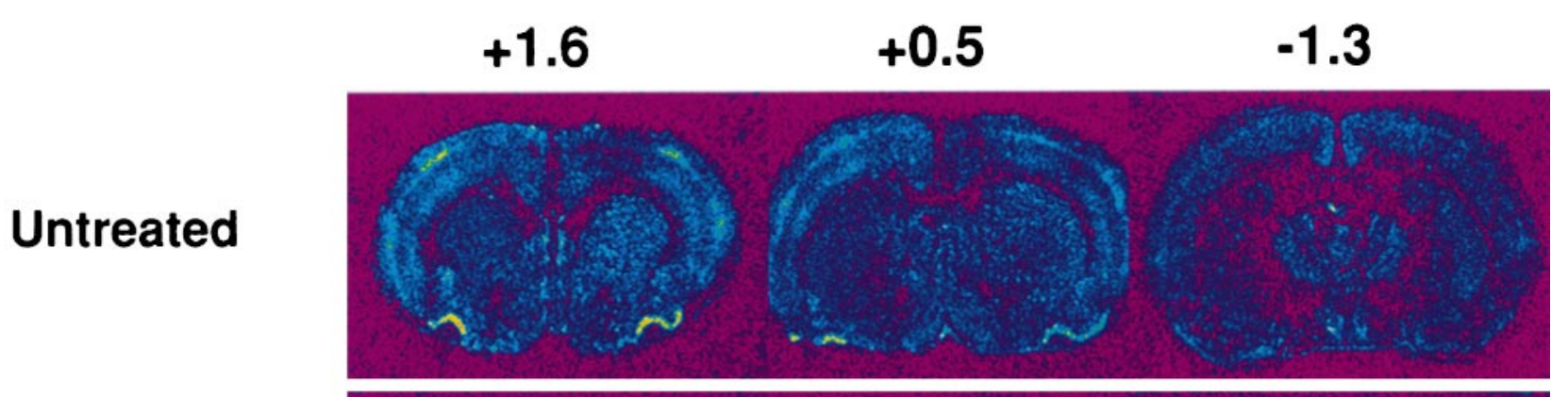

\section{Saline}

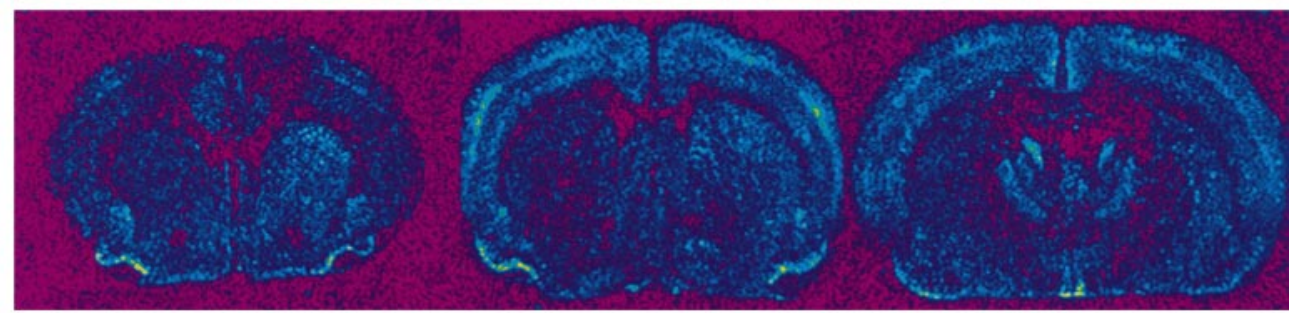

\section{Amphetamine}

Novelty
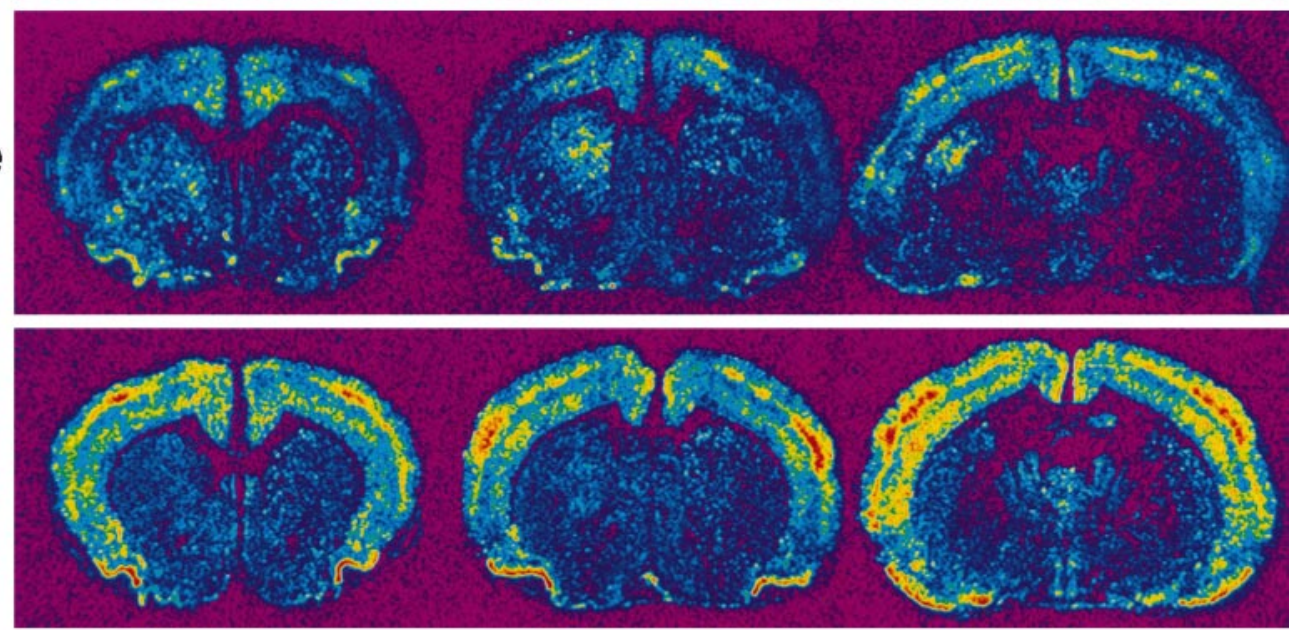

\section{Amphetamine + Novelty}

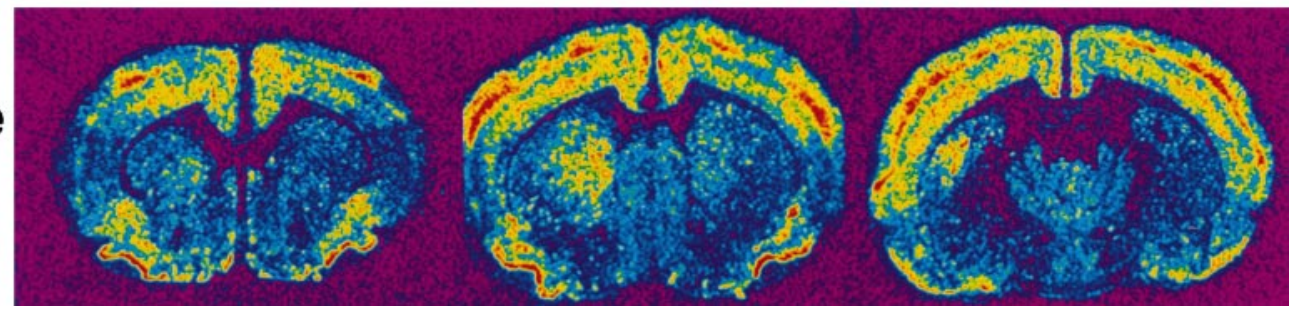

Figure 4. Representative densitograms taken from three different levels of the neuroaxis $(+1.6,+0.5$, and $-1.3 \mathrm{~mm}$ from bregma), showing the signal from hybridized ${ }^{35} \mathrm{~S}$-riboprobes for c-fos mRNA as a function of treatment and of environmental condition (see Fig. 3). Progressively greater intensity of the signal from the hybridized ${ }^{35} \mathrm{~S}$-riboprobe for c-fos mRNA is indicated by the transition from blue to yellow to red. All densitograms were oriented so that the lesion side appears on the right. The quantitative analyses of optical density values are illustrated below (see Figs. 5-7, 9-11).

nucleus accumbens the averaged data presented in Figure 5 accurately represent the relevant group differences.

Unilateral 6-OHDA lesion. Figure 7 shows the effect of the unilateral 6-OHDA lesion on c-fos expression in the caudate and in the core and shell of the nucleus accumbens. In the caudate there was a significant effect of the 6-OHDA lesion in all groups except the novelty group, but there were interesting group differences in the direction of the effect. In the untreated and saline groups c-fos mRNA levels were significantly higher on the lesion side than on the intact side $(p<0.001)$. In the novelty group c-fos mRNA levels were a little higher on the lesion side, but this effect did not reach statistical significance $(p=0.13)$. The higher levels of c-fos expression in the denervated caudate might be related to the development of denervation-induced DA receptor supersensitivity on the side of the lesion. In the two groups given amphetamine, however, the asymmetry in c-fos expression was opposite to that seen in the control groups. Indeed, both the amphetamine and the amphetamine + novelty groups had significantly higher c-fos mRNA levels on the intact than on the lesion side $(p<$ $0.001)$. This is probably attributable to the fact that amphetamine requires intact DA terminals to increase c-fos expression via activation of D1 DA receptors by endogenous DA (Berretta et al., 1992). The effect of the 6-OHDA lesion on c-fos expression in the core of the nucleus accumbens was very similar to that in the caudate (Fig. 7). In contrast, in the shell of the nucleus accumbens there was no significant effect of the lesion in any group. This 
Figure 5. c-fos mRNA levels (mean optical density \pm SEM) in different regions of the striatal complex, as a function of treatment and of environmental condition (see Fig. 3). $A-C$, One-way ANOVAs indicated significant group differences in the caudate $[A$; $\left.F_{(4,43)}=50.91 ; p<0.0001\right]$ and in the core $\left[B ; F_{(4,42)}=32.88 ; p<0.0001\right]$ and shell $[C$; $\left.F_{(4,42)}=24.42 ; p<0.0001\right]$ of the nucleus accumbens. The dotted lines refer to expected values predicted by a simple additive model of amphetamine and novelty interaction (see text). $D$, Correlation between c-fos mRNA levels in the caudate and rate of rotational behavior is shown. The dashed line refers to the overall correlation for the amphetamine-treated animals $(r=0.75 ; p<$ 0.0001 ). The solid gray and solid black lines refer to the same correlation for the amphetamine group $(r=0.68 ; p<0.02)$ and the amphetamine + novelty group $(r=0.71 ; p<$ $0.02)$, respectively. $E, F$, No significant correlation was seen for either amphetamine or amphetamine + novelty groups in either the shell $(F)$ or the core $(E)$ of the nucleus accumbens ( $p \geq 0.5$ for both). For the meaning of the symbols, see Figure 3.

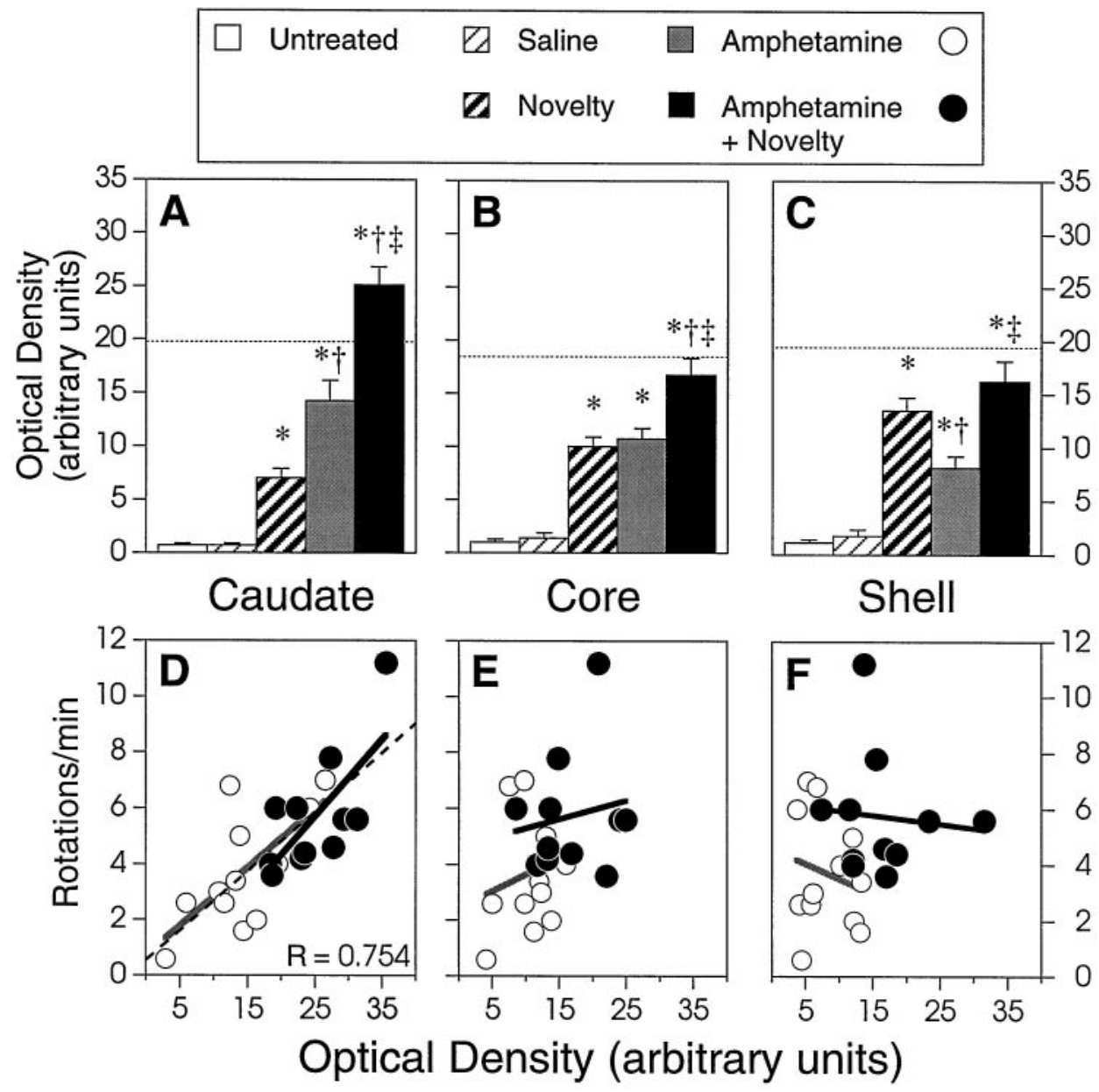

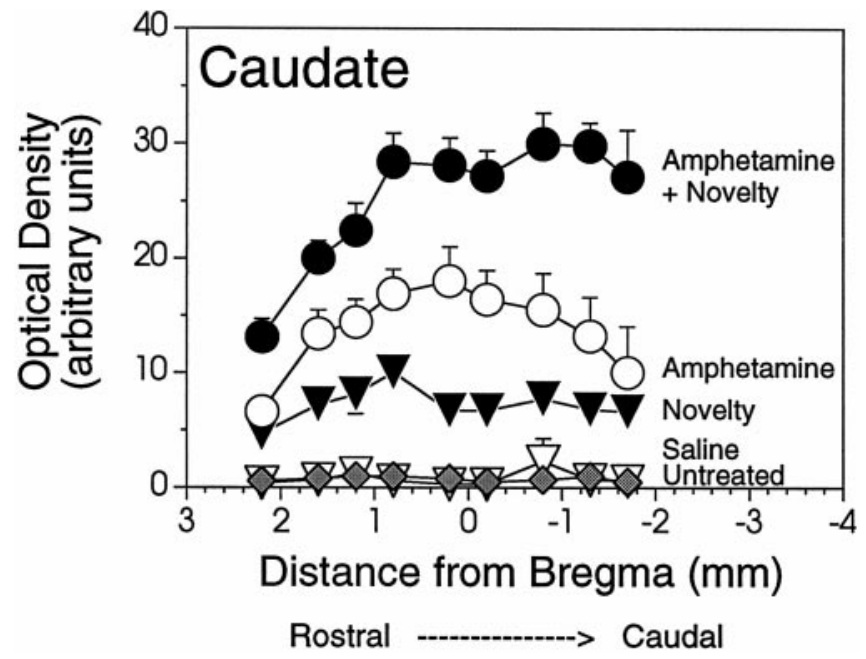

Figure 6. Rostrocaudal gradient of c-fos mRNA (mean optical density \pm SEM) in the caudate, as a function of treatment and of environmental condition (see Fig. 3).

latter observation is consistent with reports that DA fibers projecting to the shell of the nucleus accumbens are especially resistant to 6-OHDA (Zahm, 1991).

Summary. Both novelty alone and amphetamine alone significantly enhanced c-fos expression in the caudate and in the shell and core of the nucleus accumbens, but there were clear regional differences in the effects of these two manipulations. Figure 8 graphically summarizes the magnitude of the effects of novelty alone (left) and amphetamine alone (right) on c-fos expression in the three major subregions of the striatal complex. In the novelty group, c-fos mRNA levels were highest in the shell, intermediate in the core, and lowest in the caudate. In contrast, in the amphetamine group, c-fos mRNA levels were highest in the caudate (where they were significantly higher than the levels in the novelty group; $p<0.001$ ), intermediate in the core (where they were the same as the levels in the novelty group; $p=0.67$ ), and lowest in the shell (where they were significantly lower than the levels in the novelty group; $p=0.004$ ). Furthermore, within the caudate, the rostrocaudal gradient of c-fos expression differed in the two groups (see Fig. 6). Lastly, the 6-OHDA lesion had different effects on the amphetamine versus novelty groups. Amphetamineinduced c-fos expression in the caudate and in the core of the nucleus accumbens was significantly decreased on the side of the lesion, whereas this was not the case for novelty. Taken together these findings suggest that amphetamine and novelty induce c-fos expression via different mechanisms of action and perhaps in different populations of neurons (see below).

It is notable that in the caudate the association of amphetamine and novelty not only increased c-fos expression to a greater extent than did either amphetamine or novelty alone but the magnitude of this effect was significantly greater than would be predicted by a simple additive model, especially in the caudal portions of the caudate; that is, in the caudate the interaction of amphetamine and novelty appeared to be superadditive. In contrast, c-fos 


\section{Caudate}

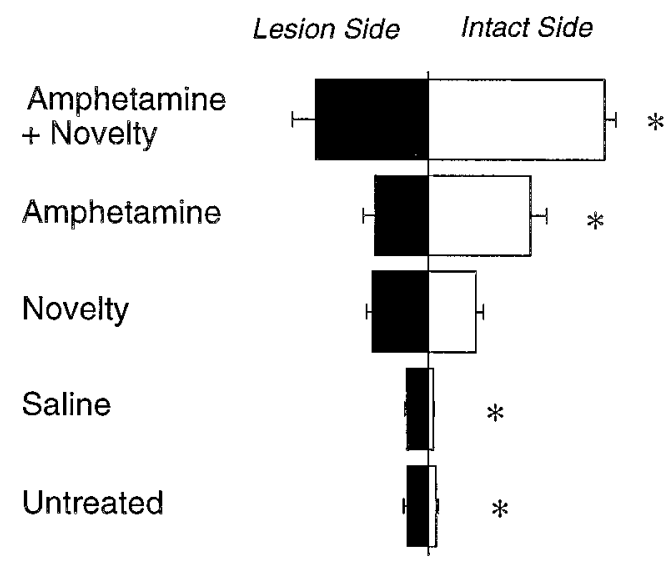

Core

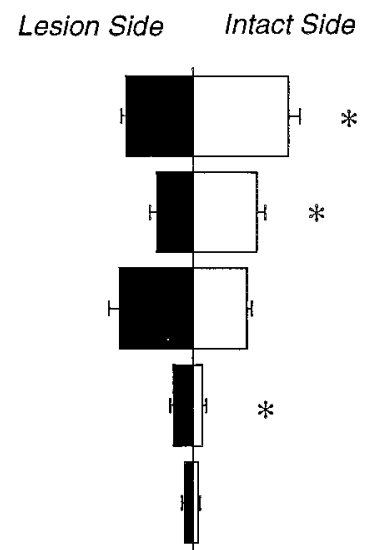

\section{Shell}

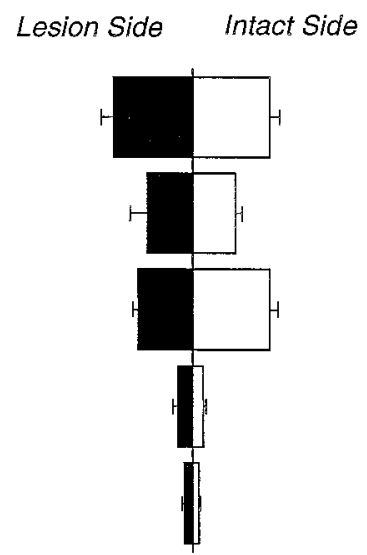

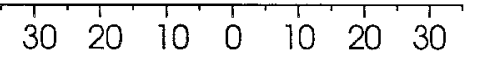

$\begin{array}{lllllll}30 & 20 & 10 & 0 & 10 & 20 & 30\end{array}$ $\begin{array}{lllllll}30 & 20 & 10 & 0 & 10 & 20 & 30\end{array}$

\section{Optical Density (arbitrary units)}

Figure 7. Effect of a unilateral 6-OHDA lesion on c-fos mRNA levels (mean optical density \pm SEM) in the caudate and in the core and shell of the nucleus accumbens, as a function of treatment and of environmental condition (see Fig. 3). Two-way ANOVAs with repeated measures on one factor indicated a significant effect of lesion in the caudate $\left[F_{(1,43)}=11.81 ; p=0.001\right]$ and in the core $\left[F_{(1,42)}=3.98 ; p=0.053\right]$ but not in the shell $\left[F_{(1,42)}=\right.$ $2.4 ; p<0.13]$ of the nucleus accumbens. There was also a group times lesion interaction in the caudate $\left[F_{(1,42)}=8.42 ; p<0.0001\right]$ and in the core $\left[F_{(4,42)}\right.$ $=6.34 ; p<0.001]$ but not in the shell $\left[F_{(1,42)}=1.13 ; p=0.36\right]$ of the nucleus accumbens. For the meaning of the asterisks, see Figure 3 .

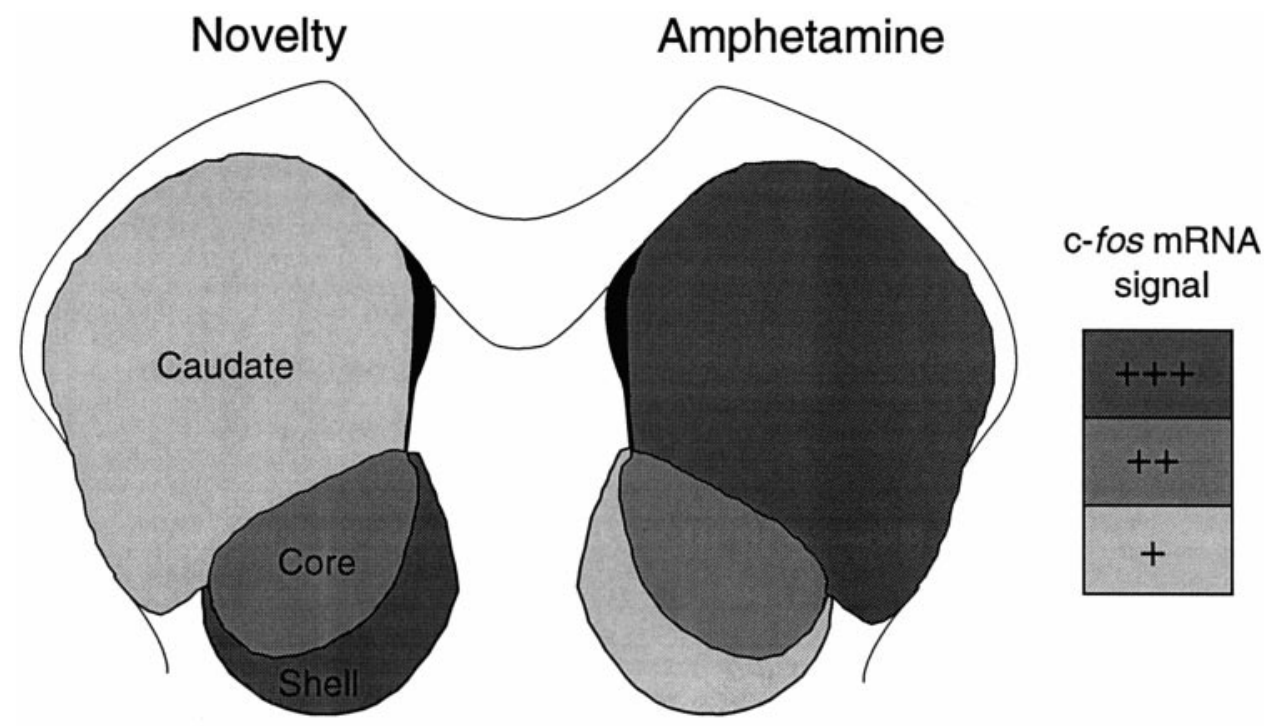

Figure 8. Schematic drawing [obtained by digital modification of a plate from Paxinos and Watson (1982)] summarizing the magnitude of the effects of novelty alone (left) and amphetamine alone (right) on c-fos expression in the three regions of the striatal complex.
mRNA levels in the shell of amphetamine + novelty animals were significantly lower than would be predicted by a simple additive model, whereas in the core they were approximately the same as would be predicted by an additive model. These data suggest that amphetamine and novelty interact in a number of different ways, and the nature of the interaction is region-specific.

\section{$c$-fos expression in the cortex and other brain areas}

Controls. c-fos mRNA levels (see Figs. 3, 9, 11) in the untreated and saline groups were quite low in all the other brain areas analyzed, with the exception of rostral levels of the piriform cortex, dorsal endopiriform nucleus, and claustrum, all of which had relatively high levels of basal expression. Furthermore, there were no significant differences between the untreated and saline groups in any region.

Novelty. Mere exposure to a novel environment produced a very large increase in c-fos expression in many of the cortical areas examined (Figs. 3, 9). This increase was particularly robust in layers IV and VI of the neocortex, in layer I of the cingulate cortex, and in layer II of the piriform cortex. Novelty also increased c-fos expression in the dorsal endopiriform nucleus, in the claustrum, and in the septum (see Fig. 11). Within the septum, novelty produced a greater effect in the dorsolateral (LSI and LSD) than in the medioventral (MS, VDB, and HDB) nuclei (see Fig. 11). Amphetamine. Amphetamine treatment in the home environ- 


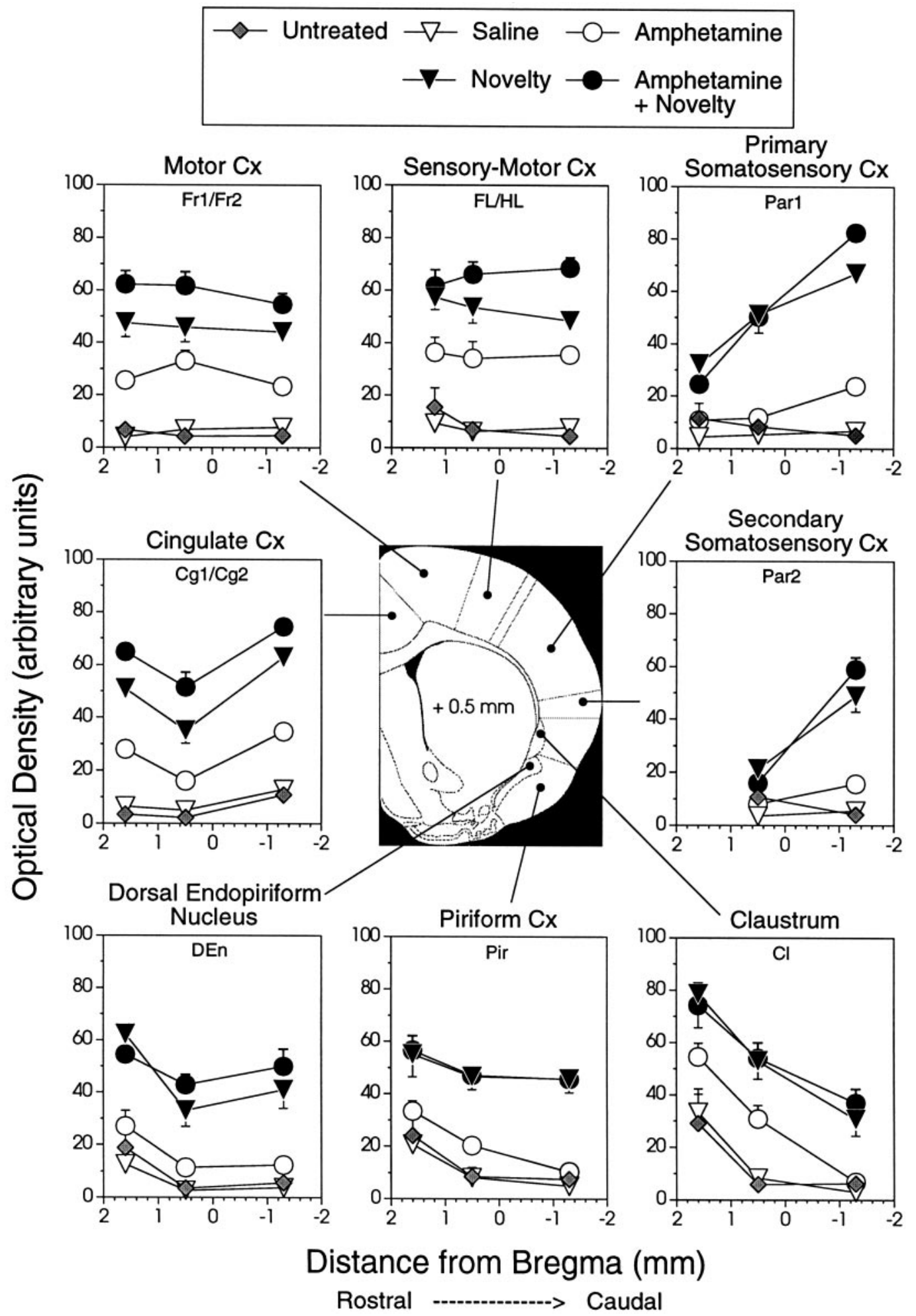

Figure 9. c-fos mRNA levels (mean optical density \pm SEM) in different cortical and subcortical regions at three different levels of the neuroaxis, as a function of treatment and of environmental condition (see Fig. 3). The center panel was obtained by digital modification of a plate from Paxinos and Watson (1982). One-way ANOVAs indicated significant group differences in all regions and at all levels $(p$ values $\leq 0.001)$, except at level +0.5 of Par 2 $(p=0.11)$. Fisher's PLSD tests gave the following results. For untreated versus saline, there were no significant differences $(p$ values $>0.3)$ in any region. For novelty versus saline, there were significant differences $(p<0.05)$ in all regions and at all levels. For amphetamine versus saline, there were significant differences at all levels of $C g 1 / C g 2, F r 1 / F r 2$, and $F L / H L$; at the most rostral level ( -1.3$)$ of Parl and Par2; and at the intermediate level ( +0.5 ) of $\mathrm{Pir}$ and $\mathrm{Cl}$. For amphetamine versus novelty, there were significant differences in all regions and at all levels, except for level +0.5 of Par 2 and level +1.6 of $\mathrm{Cl}$. For amphetamine + novelty versus saline and versus amphetamine, there were significant differences in all regions and at all levels (except for level +0.5 of $\operatorname{Par} 2)$. For amphetamine + novelty versus novelty, there were significant differences at all levels of $\mathrm{Cg} 1 / \mathrm{Cg} 2, \mathrm{Fr} 1 / \mathrm{Fr} 2$, and $\mathrm{FL} / \mathrm{HL}$; at the most rostral level $(-1.3)$ of Par1 and Par2; and at the intermediate level $(+0.5)$ of DEn.Cx, Cortex. 


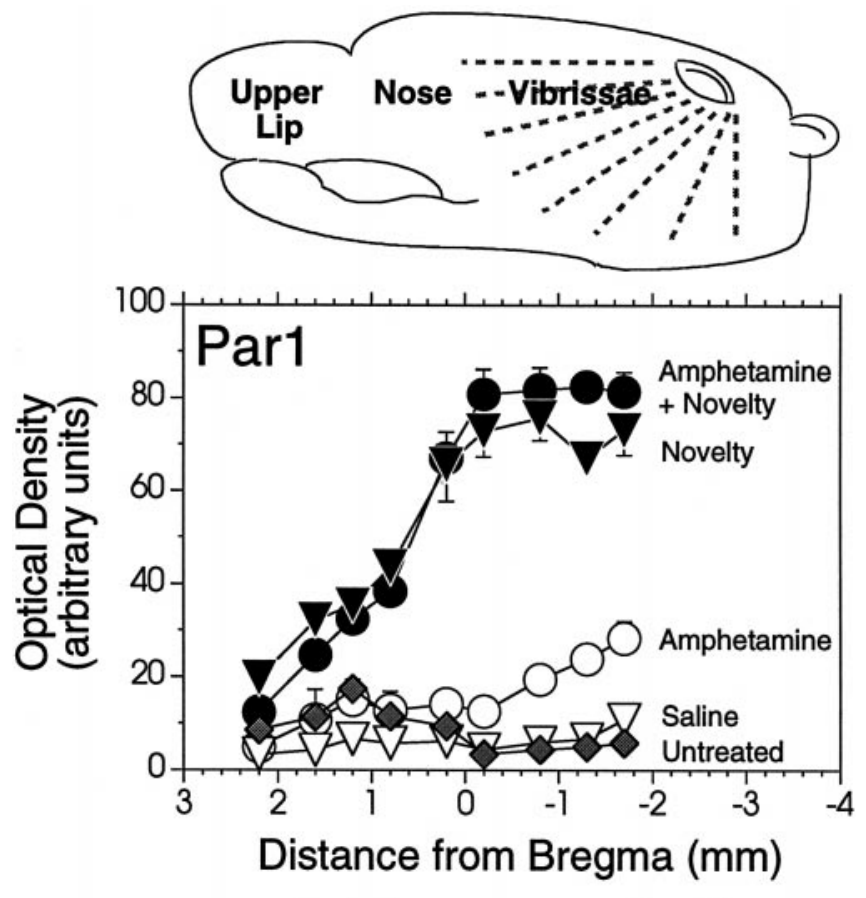

Rostral -----------> Caudal

Figure 10. Rostrocaudal gradient of c-fos mRNA (mean optical density \pm SEM) in Par1, as a function of treatment and of environmental condition (see Fig. 3). The schematic drawing [top; modified from Dawson and Killackey (1987)] illustrates the functional subdivision of Par1.

ment significantly increased c-fos mRNA levels in the cingulate cortex, the frontal cortex, and the FL and HL areas of the parietal cortex (Fig. 9). The effect of amphetamine alone was more modest in the other brain regions examined and reached statistical significance only in the most caudal levels of Par1 and Par2 and in midpiriform cortex and midclaustrum (Figs. 9, 10). Like novelty, amphetamine increased c-fos expression to the greatest extent in layers IV and VI of the neocortex. It is also obvious from Figure 9 that in essentially all the cortical regions examined [and in the septum (Fig. 11)] the effect of amphetamine alone on c-fos mRNA levels was much smaller than was the effect of novelty alone.

Amphetamine + novelty. In virtually all the cortical regions examined, amphetamine + novelty produced much higher levels of c-fos expression than did amphetamine alone, and in general the pattern and magnitude of c-fos expression in the amphetamine + novelty group was similar to that in the novelty group (Figs. 9-11). Only in a few regions was the effect of amphetamine + novelty a little greater than the effect of novelty alone (e.g., motor, sensory motor, and cingulate cortex).

Rostrocaudal gradient. Figure 9 also shows the magnitude of c-fos expression in each region as a function of rostrocaudal level. In most structures $(\mathrm{Cg} 1 / \mathrm{Cg} 2, \mathrm{Fr} 1 / \mathrm{Fr} 2, \mathrm{FL} / \mathrm{HL}, \mathrm{Pir}$, and DEn) there was no pronounced rostrocaudal gradient in c-fos expression. In the claustrum and in the somatosensory cortex, however, there was a marked rostrocaudal gradient in c-fos expression. In the claustrum c-fos mRNA levels for all groups (including control groups) were greatest in the most rostral section and decreased by approximately one-half by the most caudal section.

In contrast, there were striking group differences in the rostrocaudal gradients of c-fos expression within Par1 and Par2. Figure 10 illustrates a detailed analysis of c-fos expression in Par1 over

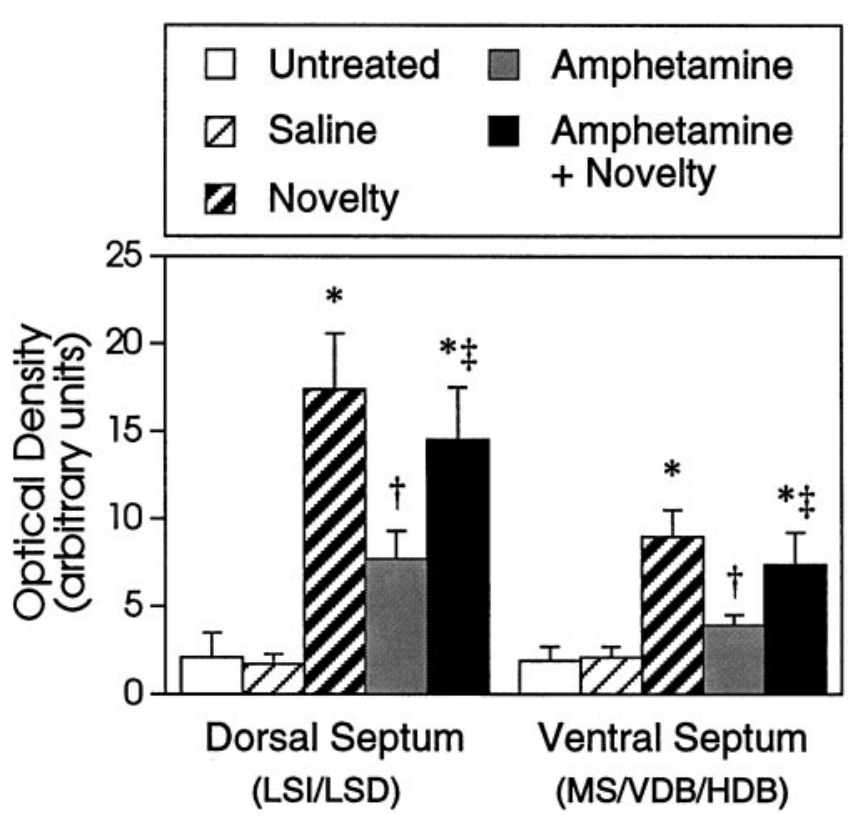

Figure 11. c-fos mRNA levels (mean optical density \pm SEM) in the septum, as a function of treatment and of environmental conditions (see Fig. 3). A one-way ANOVA indicated significant group differences in both the dorsolateral $\left[F_{(4,41)}=9.37 ; p<0.0001\right]$ and the ventromedial $\left[F_{(4,41)}\right.$ $=6.62 ; p<0.001]$ septum. For the meaning of the symbols, see Figure 3 .

nine levels $(+2.2$ to $-17 \mathrm{~mm}$ from bregma). In the untreated and saline groups optical density was homogenously low throughout the rostrocaudal extent of Par1. In the novelty group c-fos expression increased by approximately four times between +2.2 and $+0.5 \mathrm{~mm}$ from bregma and then remained high between +0.5 and $-1.7 \mathrm{~mm}$. This gradient parallels the transition from the areas of Par1 subserving the cutaneous representation of jaws, lips, and nose to those subserving the mystacial vibrissae, where layer IV is organized in "barrels" (for review, see Tracey and Waite, 1995). Indeed, c-fos expression in the novelty group was more intense in the "barrel field" cortex (Fig. 10), particularly in layer IV (see Fig. 4), than in any other region analyzed. In contrast, amphetamine alone had very little effect in Par1, although a shallow rostrocaudal gradient was evident (Fig. 10). The effect of amphetamine + novelty was essentially identical to that of novelty alone (Fig. 10).

c-fos expression in Par2 was analyzed only at two levels (Fig. 9), but the general pattern was similar to that described above for Par1. In particular, note that novelty had no effect in rostral Par2 ( $+0.5 \mathrm{~mm}$ from bregma), which subserves the jaws, lips, and nose, whereas it produced a large increase in c-fos mRNA in caudal Par2 $(-1.3 \mathrm{~mm})$, which subserves the vibrissae (for review, see Tracey and Waite, 1995).

Summary. Amphetamine produced a significant increase in c-fos expression in the cingulate cortex, in the frontal cortex, and in the areas FL/HL of the parietal cortex. Novelty, however, was much more effective than amphetamine not only in these regions but also in all other regions analyzed, including those in which amphetamine alone was ineffective. Figure 12 graphically summarizes the different patterns of c-fos expression in the novelty versus amphetamine groups. As in the striatal complex, c-fos expression in the amphetamine + novelty group was greater than that in the amphetamine group in all regions examined, but in contrast to the striatum, in many regions the effect of novelty alone was as large as the effect of amphetamine + novelty (e.g., in 


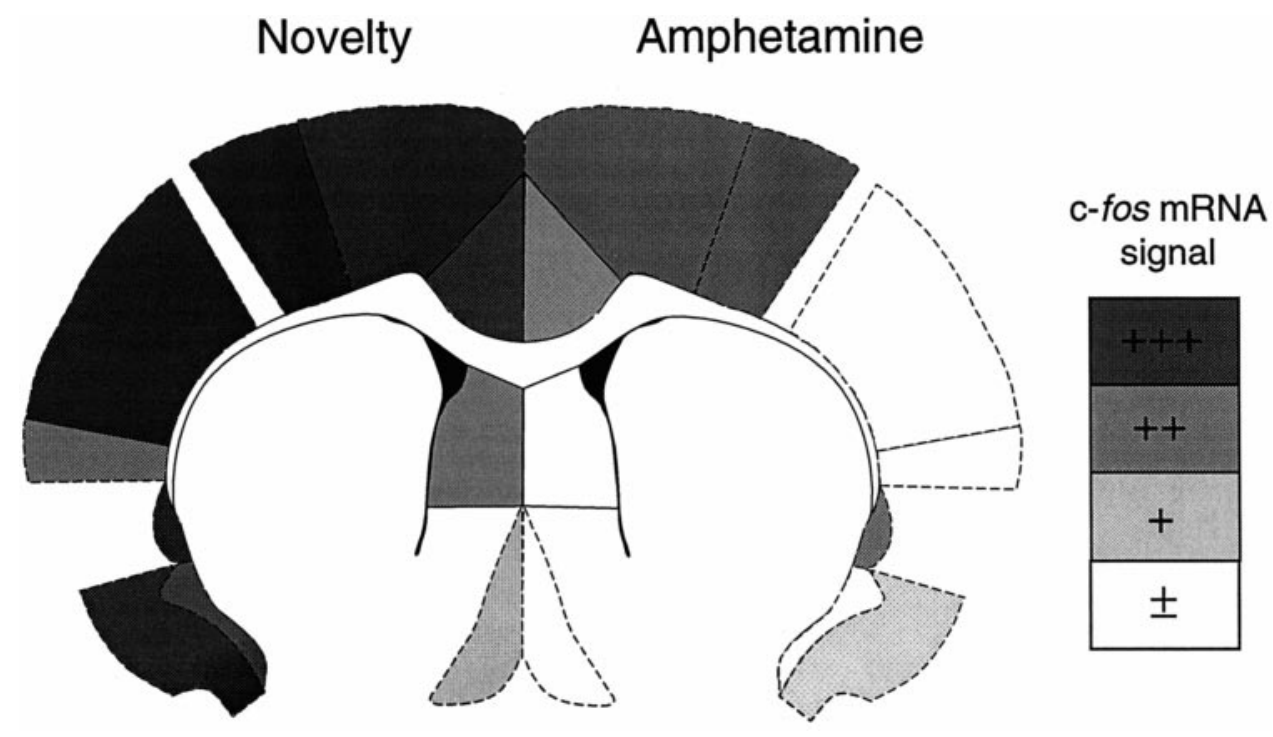

Figure 12. Schematic drawing [obtained by digital modification of a plate from Paxinos and Watson (1982)] summarizing the magnitude of the effects of novelty alone (left) and amphetamine alone (right) on c-fos expression in various cortical and subcortical regions $(+0.5 \mathrm{~mm}$ from bregma). Also see Figures 9 and 11.

Par1, Par2, Pir, DEn, claustrum, and septum). Only in the Cg1/ $\mathrm{Cg} 2$, Fr1/Fr2, and FL/HL was the effect of amphetamine + novelty marginally greater than the effect of novelty alone. That is, in most cortical regions (and the septum) the effect of amphetamine + novelty on c-fos expression seems to be attributable almost entirely to the effect of novelty alone (although from the present data we do not know whether these two manipulations in fact induced c-fos in the same cell populations).

It should be noted that the group differences in c-fos expression in the cortex (e.g., Par1) are not associated with group differences in the magnitude of the effect of the various treatments on rotational behavior. Both amphetamine alone and amphetamine + novelty produced much more vigorous rotational behavior than did mere exposure to a novel environment (Fig. 3), but in all regions (Fig. 9) the effect of novelty alone on c-fos expression was much greater than the effect of amphetamine alone and was comparable with the effect of amphetamine + novelty.

\section{Plasma corticosterone}

Exposure to environmental novelty produces neuroendocrine changes similar to those usually associated with conditions of stress, such as activation of the hypothalamo-pituitary-adrenal axis (HPA) and the release of corticosterone (Friedman and Ader, 1967; Hennessy et al., 1977), as well as the production of corticotropin-releasing hormone-dependent hypertension, tachicardia, and hyperthermia (Morimoto et al., 1993). Similarly, amphetamine greatly increases corticosterone secretion (Bhattacharya and Marks, 1969; Knych and Eisenberg, 1979), and circulating corticosterone has been implicated in amphetamineinduced behaviors (Piazza and Le Moal, 1997). Plasma corticosterone levels were quantified, therefore, to assess whether the facilitation in the behavioral activating effects of amphetamine seen in a novel versus a home environment might be related to differences in the amount of corticosterone secreted under these different environmental conditions.

Figure 13 shows the concentration of corticosterone in plasma obtained from the animals used in the in situ hybridization experiment. There was no significant difference between the untreated and saline groups ( $p=0.91)$, indicating that an intraperitoneal injection of saline in well-handled animals has little if any effect on the HPA axis. In both the novelty and the amphet-

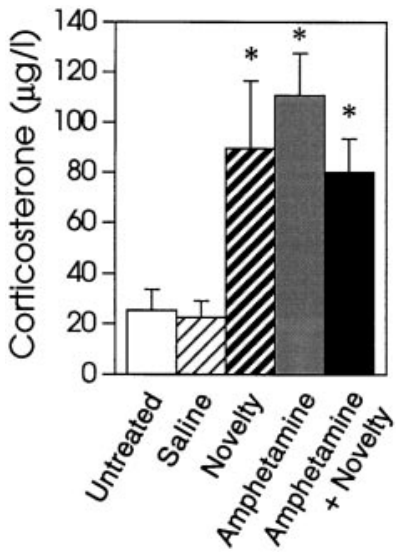

Figure 13. Plasma corticosterone (means \pm SEM) as a function of treatment and of environmental condition (see Fig. 3). A one-way ANOVA indicated significant group differences $\left[F_{(4,43)}=4.96 ; p=0.002\right]$. For the meaning of the asterisks, see Figure 3.

amine groups there was a significant increase in plasma corticosterone $(p=0.003$ and $p=0.014$, respectively), but there were no differences between the two groups $(p=0.37)$. Furthermore, the effects of amphetamine and novelty were not additive, as indicated by the fact that plasma corticosterone levels in the amphetamine + novelty group ( $p=0.03$ vs the untreated group) were similar to those produced by amphetamine alone $(p=0.77)$ or novelty alone $(p=0.25)$.

These findings suggest that corticosterone does not play a critical role in the ability of novelty to modulate amphetamineinduced psychomotor activation, a conclusion that is consistent with our previous report that adrenalectomy does not block the effect of novelty on the rotational response to amphetamine (Badiani et al., 1995b).

\section{DISCUSSION}

We reported three major findings. (1) Consistent with previous studies, environmental novelty enhanced the psychomotor activating effects of amphetamine (Badiani et al., 1995a,b,c, 1997). Because environmental novelty has no effect on plasma or striatal amphetamine concentrations (Badiani et al., 1997), the most likely explanation for this effect is that the neurobiological impact 
of amphetamine varies depending on the circumstances surrounding its administration. (2) A study using in situ hybridization for c-fos mRNA confirmed that indeed the pattern of neuronal activation produced by an amphetamine treatment at home differs from that seen when amphetamine is administered in association with environmental novelty, especially in the striatum. (3) Even though c-fos expression in the striatal complex was much greater when amphetamine was administered in association with environmental novelty than when administered at home, there was no effect of environmental novelty on amphetaminestimulated DA release in either the caudate nucleus or the nucleus accumbens. This suggests that environmental novelty does not alter c-fos expression by modulating the primary neuropharmacological action of amphetamine (i.e., increasing DA release) in the striatum but must involve other mechanisms.

The finding that amphetamine increased c-fos expression throughout the striatal complex is consistent with previous reports that a variety of potentially addictive drugs, including morphine, cocaine, and amphetamine, induce immediate early genes in the caudate nucleus and the nucleus accumbens (Chang et al., 1988; Graybiel et al., 1990; for review, see Harlan and Garcia, 1998). The ability of amphetamine to induce c-fos in the striatum is thought to be primarily caused by its ability to release endogenous DA, which via activation of D1 DA receptors triggers a transductional cascade culminating in the expression of the c-fos gene (Berretta et al., 1992; Konradi et al., 1994). The fact that the ability of amphetamine to induce c-fos was significantly reduced in the striatum with a 6-OHDA lesion is in agreement with the notion that this is a DA-dependent effect.

The unique finding reported here is that the effect of amphetamine on c-fos expression was very different when amphetamine was given in association with environmental novelty relative to when it was given in the home cage, even though these two environments were physically identical. Furthermore, this effect was seen in every cortical and subcortical structure examined. Amphetamine + novelty produced significantly greater c-fos mRNA levels than amphetamine alone in the caudate, the core and shell of the nucleus accumbens, the sensory motor cortex, the somatosensory cortex, the cingulate cortex, the dorsal endopiriform cortex, the piriform cortex, the claustrum, and the dorsal and ventral septum. In most structures the effect of amphetamine + novelty was at least twice that of amphetamine alone, and in some cortical regions amphetamine alone had no (or little) effect on c-fos expression, but amphetamine + novelty produced robust c-fos expression (e.g., Par1 and Par2).

This study was designed to assess the overall level of activation in different brain regions and therefore provided no information on whether the effects of novelty and/or amphetamine involved the same neuronal populations or different populations. There is some indirect evidence, however, that the nature of the interaction between amphetamine and novelty in enhancing c-fos expression was regionally specific. From a purely quantitative point of view the contribution of novelty to the effect of amphetamine seems to be relatively simple in the cortex and septum. In these regions novelty produced much more robust c-fos expression than did exposure to amphetamine alone, and most importantly, the effect of novelty was comparable in magnitude with that of amphetamine + novelty. Even the marked rostrocaudal gradient in c-fos expression seen in some structures (e.g., see area Par1 of the parietal cortex, Fig. 10) was identical in the novelty and the amphetamine + novelty groups. The ability of environmental novelty to produce c-fos expression in the cortex, in the striatum, and in the septum may be related to its effect as a stressor. Similar changes in c-fos expression have been reported not only in rats exposed to a novel environment (Handa et al., 1993; Papa et al., 1993) but also in rats subjected to stressors such as swim stress, restraint, or footshock (D’Costa et al., 1991; Pezzone et al., 1992; Cullinan et al., 1995). The most parsimonious conclusion, therefore, is that in the cortex and septum the increased levels of c-fos mRNA seen when amphetamine is given in association with environmental novelty is almost entirely attributable to the effect of novelty, possibly because of its stress-inducing properties. This conclusion relies, however, on the assumption that novelty and amphetamine induce c-fos mRNA in the same populations of cortical neurons, an assumption that requires verification. Double in situ hybridization studies might unveil the presence of unique populations of cortical neurons responsive to both amphetamine and novelty, which may prove of particular importance for the development of long-term neuroplasticity (see below).

In the striatum the interaction between amphetamine and novelty seems to be more complex, even at a purely quantitative level of analysis. As stated in the Results, although novelty, amphetamine, and amphetamine + novelty all increased c-fos mRNA levels in the striatum, there were a number of group differences that, taken together, suggest that in the striatum amphetamine and novelty induce c-fos via different mechanisms and perhaps in different cell populations, and it is even possible that the combination of amphetamine + novelty engages different circuitry than either amphetamine or novelty alone. We have recently obtained evidence in support of this hypothesis (Badiani et al., 1998). Using double in situ hybridization of striatal neurons with probes for c-fos and for D1 or D2 receptor mRNA, we found that amphetamine alone produces a significant increase in c-fos expression only in D1 neurons. In contrast, the association of amphetamine and environmental novelty increases c-fos expression both in D1 (to a greater extent than amphetamine alone) and in D2 neurons. Given that different neuronal populations, with different patterns of connectivity, are thought to express D1 versus D2 receptors (Gerfen et al., 1990; Curran and Watson, 1995; Le Moine and Bloch, 1995), this provides compelling evidence in support of the notion that the neural circuitry engaged by amphetamine indeed varies as a function of environmental context.

This study does not address the potential mechanisms by which amphetamine and environmental novelty interact to induce c-fos expression. Nevertheless, it is interesting to note that in the amphetamine + novelty group the rostrocaudal gradient of c-fos expression in Par1 was similar to that seen in the caudate (Figs. 6, 10). This raises the possibility that environmental novelty modulates amphetamine-induced c-fos expression in the caudate via glutamatergic afferents from the cortex. There are direct connections between adjacent cortical and striatal areas (for review, see Heimer et al., 1995), and activation of the somatosensory cortex can induce c-fos expression in the striatum of the squirrel monkey (Parthasarathy and Graybiel, 1997). Furthermore, the effect of amphetamine on c-fos expression in the striatum has been shown to depend on postsynaptic NMDA receptors (Snyder-Keller, 1991; Konradi et al., 1996) and to require intact corticostriatal projections (Cenci and Björklund, 1993).

Finally, it is worth noting that the ability of psychomotor stimulant drugs to induce immediate early genes may contribute to their ability to produce the very persistent neuroadaptations responsible for phenomena such as behavioral sensitization (Nestler and Duman, 1995). It is especially relevant that low doses of 
amphetamine or cocaine produce robust sensitization only when these drugs are administered in association with environmental novelty (Crombag et al., 1996; Browman et al., 1998a,b). One can speculate, therefore, that the effect of novelty on susceptibility to drug sensitization is related, at least in part, to its ability to modulate gene expression and to the recruitment of additional neural circuitry. For example, our data indicate that animals that receive amphetamine in a novel environment exhibit strong neuronal activation not only in the striatum, as found in animals treated with amphetamine at home, but also in cortical areas that have been implicated in the development of both drug-induced and/or stress-induced sensitization, such as the cingulate and prefrontal cortex (Hamamura and Fibiger, 1993; Gresch et al., 1994; Banks and Gratton, 1995; Wolf et al., 1995; Robinson and Kolb, 1997; Pierce et al., 1998) and the parietal cortex (Curran et al., 1996). Experiments are in progress to investigate whether novelty-induced enhancement of amphetamine sensitization is accompanied by long-term changes in the regulation of immediate early genes in these cortical areas.

In closing, the present study clearly establishes that the behavioral and neurobiological consequences of amphetamine treatment vary as a function of the circumstances surrounding its administration. Research on how environmental factors modulate the neurobiological effects of psychoactive drugs is in its infancy, but such research will be critical to better understand how pharmacological, environmental, and organismic variables interact in shaping individual responsivity to psychoactive drugs and, in the case of potentially addictive drugs, the propensity to addiction (Zinberg, 1984; Robinson and Berridge, 1993).

\section{REFERENCES}

Badiani A, Anagnostaras S, Robinson TE (1995a) The development of sensitization to the psychomotor stimulant effects of amphetamine is enhanced in a novel environment. Psychopharmacology (Berl) 117:443-452.

Badiani A, Morano MI, Akil H, Robinson TE (1995b) Circulating adrenal hormones are not necessary for the development of sensitization to the psychomotor activating effects of amphetamine. Brain Res 673:13-24.

Badiani A, Browman KE, Robinson TE (1995c) Influence of novel versus home environments on sensitization to the psychomotor stimulant effects of cocaine and amphetamine. Brain Res 674:291-298.

Badiani A, Camp DM, Robinson TE (1997) Enduring enhancement of amphetamine sensitization by drug-associated environmental stimuli. J Pharmacol Exp Ther 282:787-794.

Badiani A, Oates MM, Day HEW, Watson S, Akil H, Robinson TE (1998) Effects of environmental novelty on amphetamine-induced c-fos expression in D1 and D2 striatal neurons. Soc Neurosci Abstr 24:954.

Banks KE, Gratton A (1995) Possible involvement of medial prefrontal cortex in amphetamine-induced sensitization of mesolimbic dopamine function. Eur J Pharmacol 282:157-167.

Bardo MT, Bowling SL, Pierce RC (1990) Changes in locomotion and dopamine neurotransmission following amphetamine, haloperidol, and exposure to novel environmental stimuli. Psychopharmacology (Berl) 101:338-343.

Barrett JE (1987) Nonpharmacological factors determining the behavioral effects of drugs. In: Psychopharmacology: the third generation of progress (Meltzer HY, ed), pp 1493-1501. New York: Raven.

Berretta S, Robertson HA, Graybiel AM (1992) Dopamine and glutamate agonists stimulate neuron-specific expression of Fos-like protein in the striatum. J Neurophysiol 68:767-777.

Bhattacharya AN, Marks BH (1969) Effects of pargyline and amphetamine upon acute stress responses in rats. Proc Soc Exp Biol Med 130:1194-1198.

Browman KE, Badiani A, Robinson TE (1995) Striatal dopamine following an acute treatment with amphetamine in a NOVEL versus HOME environment. Soc Neurosci Abstr 21:2090.

Browman KE, Badiani A, Robinson TE (1998a) The influence of environment on the induction of sensitization to the psychomotor activating effects of intravenous cocaine in rats is dose-dependent. Psychopharmacology (Berl) 137:90-98.

Browman KE, Badiani A, Robinson TE (1998b) Modulation of amphetamine sensitization by the circumstances surrounding drug administration: dose-effect relations. J Pharmacol Exp Ther, in press.

Cenci MA, Björklund A (1993) Transection of corticostriatal afferents reduces amphetamine- and apomorphine-induced striatal Fos expression and turning behavior in unilaterally 6-hydroxydopamine-lesioned rats. Eur J Neurosci 5:1062-1070.

Chang SL, Squinto SP, Harlan RE (1988) Morphine activation of c-fos expression in rat brain. Biochem Biophys Res Commun 157:698-704.

Crombag HS, Badiani A, Robinson TE (1996) Signalled versus unsignalled intravenous amphetamine: large differences in the acute psychomotor response and sensitization. Brain Res 722:227-231.

Cullinan WE, Herman JP, Battaglia DF, Akil H, Watson SJ (1995) Pattern and time course of immediate early gene expression in rat brain following acute stress. Neuroscience 64:477-505.

Curran EJ, Watson Jr SJ (1995) Dopamine receptor mRNA expression patterns by opioid peptide cells in the nucleus accumbens of the rat: a double in situ hybridization study. J Comp Neurol 361:57-76.

Curran EJ, Akil H, Watson Jr SJ (1996) Psychomotor stimulant- and opiate-induced c-fos mRNA expression patterns in the rat forebrain: comparisons between acute drug treatment and a drug challenge in sensitized animals. Neurochem Res 21:1425-1435.

Dawson DR, Killackey HP (1987) The organization and mutability of the forepaw and hindpaw representations in the somatosensory cortex of the neonatal rat. J Comp Neurol 256:246-256.

Day HEW, Akil H (1996) Differential pattern of c-fos mRNA in rat brain following central and systemic administration of interleukin-1beta: implications for mechanism of action. Neuroendocrinology 63:207-218.

D'Costa A, Breese CR, Boyd RL, Booze RM, Sonntag WE (1991) Attenuation of Fos-like immunoreactivity induced by a single electroconvulsive shock in brains of aging mice. Brain Res 567:204-211.

Dragunow M, Faull R (1989) The use of c-fos as a metabolic marker in neuronal pathway tracing. J Neurosci Methods 29:261-265.

Dragunow M, Robertson HA (1987) Kindling stimulation induces c-fos protein(s) in granule cells of the rat dentate gyrus. Nature 329:441-442.

Falk JL, Feingold DA (1987) Environmental and cultural factors in the behavioral actions of drugs. In: Psychopharmacology: the third generation of progress (Meltzer HY, ed), pp 1503-1510. New York: Raven.

Friedman SB, Ader R (1967) Adrenocortical response to novelty and noxious stimulation, Neuroendocrinology 2:209-212.

Gerfen CR, Engber TM, Mahan LC, Susel Z, Chase TN, Monsma Jr FJ, Sibley DR (1990) D1 and D2 dopamine receptor-regulated gene expression of striatonigral and striatopallidal neurons. Science 250:1429-1432.

Graybiel AM, Moratalla R, Robertson HA (1990) Amphetamine and cocaine induce drug specific activation of the c-fos gene in striosome matrix compartments and limbic subdivisions of the striatum. Proc Natl Acad Sci USA 87:6912-6916.

Gresch PJ, Sved AF, Zigmond MJ, Finlay JM (1994) Stress-induced sensitization of dopamine and norepinephrine efflux in medial prefrontal cortex of the rat. J Neurochem 63:575-583.

Hamamura T, Fibiger HC (1993) Enhanced stress-induced dopamine release in the prefrontal cortex of amphetamine-sensitized rats. Eur J Pharmacol 237:65-71.

Handa RJ, Nunley KM, Bollnow MR (1993) Induction of c-fos mRNA in the brain and anterior pituitary gland by a novel environment. NeuroReport 4:1079-1082.

Harlan RE, Garcia MM (1998) Drugs of abuse and immediate-early genes in the forebrain. Mol Neurobiol 16:221-267.

Hefti F, Melamed E, Wurtman RJ (1980a) Partial lesions of the dopaminergic nigrostriatal system in rat brain: biochemical characterization. Brain Res 195:123-137.

Hefti F, Melamed E, Sahakian BJ, Wurtman RJ (1980b) Circling behavior in rats with partial, unilateral nigro-striatal lesions: effect of amphetamine, apomorphine, and DOPA. Pharmacol Biochem Behav 12:185-188.

Heimer L, Zahm DS, Alheid GF (1995) Basal ganglia. In: The rat nervous system, 2nd Edition (Paxinos G, ed), pp 689-704. San Diego: Academic.

Hennessy JW, Levin R, Levine S (1977) Influence of experiential factors and gonadal hormones on pituitary-adrenal response of the mouse to novelty and electric shock. J Comp Physiol Psychol 91:770-777. 
Kelleher RT, Morse WH (1968) Determinants of the specificity of behavioral effects of drugs. Ergeb Physiol 60:1-56.

Knych ET, Eisenberg RM (1979) Effect of amphetamine on plasma corticosterone in the conscious rat. Neuroendocrinology 29:110-118.

Konradi C, Cole RL, Heckers S, Hyman SE (1994) Amphetamine regulates gene expression in rat striatum via transcription factor CREB. J Neurosci 14:5623-5634.

Konradi C, Leveque JC, Hyman SE (1996) Amphetamine and dopamine-induced immediate early gene expression in striatal neurons depends on postsynaptic NMDA receptors and calcium. J Neurosci 16:4231-4239.

Le Moal M (1995) Mesolimbic dopaminergic neurons: functional and regulatory roles. In: Psychopharmacology: the fourth generation of progress (Bloom FE, Kupfer DJ, eds), pp 283-294. New York: Raven.

Le Moine C, Bloch B (1995) D1 and D2 dopamine receptor gene expression in the rat striatum: sensitive cRNA probes demonstrate prominent segregation of D1 and D2 mRNAs in distinct neuronal populations of the dorsal and ventral striatum. J Comp Neurol 355:418-426.

Morgan JI, Curran T (1991) Stimulus-transcription coupling in the nervous system: involvement of the inducible proto-oncogenes fos and jun. Annu Rev Neurosci 14:421-451.

Morimoto A, Nakamori T, Morimoto K, Tan N, Murakami N (1993) The central role of corticotrophin-releasing factor (CRF-41) in psychological stress in rats. J Physiol (Lond) 460:221-229.

Nestler EJ, Duman RS (1995) Intracellular messenger pathways as mediator of neural plasticity. In: Psychopharmacology: the fourth generation of progress (Bloom FE, Kupfer DJ, eds), pp 695-704. New York: Raven.

Papa M, Pellicano MP, Welzl H, Sadile AG (1993) Distributed changes in c-Fos and c-Jun immunoreactivity in the rat brain associated with arousal and habituation to novelty. Brain Res Bull 32:509-515.

Parthasarathy HB, Graybiel AM (1997) Cortically driven immediateearly gene expression reflects modular influence of sensorimotor cortex on identified striatal neurons in the squirrel monkey. J Neurosci 17:2477-2491.

Paxinos G, Watson C (1982) The rat brain in stereotaxic coordinates, 2nd Edition. San Diego: Academic.

Pezzone MA, Lee WS, Hoffman GE, Rabin BS (1992) Induction of c-Fos immunoreactivity in the rat forebrain by conditioned and unconditioned aversive stimuli. Brain Res 597:41-50.

Piazza PV, Le Moal M (1997) Glucocorticoids as a biological substrate of reward: physiological and pathophysiological implications. Brain Res Rev 25:359-372.

Pierce RC, Reeder DC, Hicks J, Morgan ZR, Kalivas PW (1998) Ibo- tenic acid lesions of the dorsal prefrontal cortex disrupt the expression of behavioral sensitization to cocaine. Neuroscience 82:1103-1114.

Robinson TE (1984) Behavioral sensitization: characterization of enduring changes in rotational behavior produced by intermittent injections of amphetamine in male and female rats. Psychopharmacology (Berl) 84:466-475.

Robinson TE, Berridge KC (1993) The neural basis of drug craving: an incentive-sensitization theory of addiction. Brain Res Rev 18:247-291.

Robinson TE, Camp DM (1991) The feasibility of repeated microdialysis for within-subjects design experiments: studies on the mesostriatal dopamine system. In: Microdialysis in the neurosciences (Robinson TE, Justice Jr JB, eds), pp 189-228. Amsterdam: Elsevier Science.

Robinson TE, Kolb B (1997) Persistent structural modifications in nucleus accumbens and prefrontal cortex neurons produced by previous experience with amphetamine. J Neurosci 17:8491-8497.

Segal DS, Kuczenski R (1994) Behavioral pharmacology of amphetamine. In: Amphetamine and its analogs: psychopharmacology, toxicology, and abuse (Cho AK, Segal DS, eds), pp 115-150. San Diego: Academic.

Seiden LS, Sabol KE, Ricaurte GA (1993) Amphetamine: effects on catecholamine systems and behavior. Annu Rev Pharmacol Toxicol 33:639-677.

Snyder-Keller AM (1991) Striatal c-fos induction by drugs and stress in neonatally dopamine-depleted rats given nigral transplants: importance of NMDA activation and relevance to sensitization phenomena. Exp Neurol 113:155-165.

Tracey DJ, Waite PME (1995) Somatosensory system. In: The rat nervous system, 2nd Edition (Paxinos G, ed), pp 689-704. San Diego: Academic.

Ungerstedt U, Arbuthnott GW (1970) Quantitative recording of rotational behavior in rats after 6-hydroxy-dopamine lesions of the nigrostriatal dopamine system. Brain Res 24:485-493.

Wise RA, Bozarth MA (1987) A psychomotor stimulant theory of addiction. Psychol Rev 94:469-492.

Wolf ME, Dahlin SL, Hu XT, Xue CJ, White K (1995) Effects of lesions of prefrontal cortex, amygdala, or fornix on behavioral sensitization to amphetamine: comparison with $\mathrm{N}$-methyl-D-aspartate antagonists. Neuroscience 69:417-439.

Zahm DS (1991) Compartments in rat dorsal and ventral striatum revealed following injection of 6-hydroxydopamine into the ventral mesencephalon. Brain Res 552:164-169.

Zinberg NE (1984) Drug, set, and setting: the basis for controlled intoxicant use. New Haven, CT: Yale UP. 